Check for updates

Cite this: RSC Adv., 2019, 9, 33080

\title{
Effect of template type on the preparation of the emeraldine salt form of polyaniline (PANI-ES) with horseradish peroxidase isoenzyme C (HRPC) and hydrogen peroxide $\uparrow$
}

\author{
Tomoyuki Fujisaki, (D) ab Keita Kashima, (DD ab Sandra Serrano-Luginbühl, ${ }^{a}$ \\ Reinhard Kissner, (D) Danica Bajuk-Bogdanović, (D) Maja Milojević-Rakić, ${ }^{\mathrm{d}}$ \\ Gordana Ćirić-Marjanović, (D) ${ }^{d}$ Stephan Busato, (D) e Erlantz Lizundia (D) afg \\ and Peter Walde (D)*a
}

\begin{abstract}
Horseradish peroxidase isoenzyme $\mathrm{C}$ (HRPC) is often used as catalyst for the preparation of the conductive emeraldine salt form of polyaniline (PANI-ES) from aniline and hydrogen peroxide $\left(\mathrm{H}_{2} \mathrm{O}_{2}\right)$ in the presence of anionic templates in aqueous solution. Here, a direct comparison of three types of soft templates was made, (i) the sodium salt of sulfonated polystyrene (SPS), (ii) micelles from sodium dodecylbenzenesulfonate (SDBS), and (iii) vesicles from either a 1:1 molar mixture of SDBS and decanoic acid or from AOT (sodium bis(2-ethylhexyl)sulfosuccinate). Based on UV/vis/NIR, EPR and Raman spectroscopy measurements all three types of templates are similarly suitable, with advantages of the two vesicle systems in terms of aniline conversion degree and radical content in the final PANI-ES product. First experiments with sulfated cellulose nanocrystals (CNCs) indicate that they are promising rigid templates for the preparation of electroconductive PANI-ES-coated cellulose materials or devices.
\end{abstract}

Received 8th August 2019

Accepted 5th October 2019

DOI: $10.1039 / c 9 r a 06168 a$

rsc.li/rsc-advances electroconductive, emeraldine salt form, abbreviated as PANIES. ${ }^{\mathbf{1 , 2 , 1 2 - 1 6}}$ The ideal PANI-ES molecules consist of tetraaniline repeating units in their half-reduced and half-oxidised, protonated state, see Scheme 1. The chemical structure of the counter anion (also called dopant, $\mathrm{A}^{-}$in Scheme 1) has an influence on the conductivity and processibility of materials prepared from PANI-ES molecules. ${ }^{17}$ Bulky dopants with sulfonate groups were found to be particularly good dopants to improve the dispersibility of PANI-ES in water, e.g., camphor sulfonate ${ }^{\mathbf{1 8 , 1 9}}$ or bis(2-ethylhexyl)sulfosuccinate (the sodium salt is known as AOT, Scheme 1). ${ }^{\mathbf{2 0 2}}$ Standard methods for preparing PANI-ES are based on the chemical oxidation of aniline with a strong oxidant (e.g. ammonium peroxodisulfate) at strongly acidic conditions $(\mathrm{pH}<2.5) .{ }^{1,22}$

In $1998 / 1999$ the $\mathrm{HRP} / \mathrm{H}_{2} \mathrm{O}_{2}$-catalysed polymerisation of aniline to PANI-ES was attempted as environmentally friendly approach, and it was shown that the presence of anionic additives, so-called "templates" is important for obtaining products with PANI-ES features. ${ }^{23-25}$ The templates are additives which have a positive influence on the desired outcome of the reaction in terms of chemical structure and colloidal product stability (and processability), acting in the case of PANI-ES formation also as counter ions (dopants). The first template used was sulfonated polystyrene (SPS) and the reaction was carried out successfully at $\mathrm{pH}=4.0$ or 4.3 and at room temperature (RT). ${ }^{24,25}$ Since this pioneering work, SPS $^{26,27}$ and other anionic $\dagger$ Electronic supplementary information (ESI) available. See DOI:

$10.1039 /$ c9ra06168a Department of Materials Chemistry and Bioengineering, National Institute Technology, Oyama College, 771 Ohaza-Nakakuki, Oyama, Tochigi 323-0806, Japan

${ }^{e}$ Department of Materials, Laboratory for Soft Materials, ETH Zurich, Vladimir-PrelogWeg 5, 8093 Zürich, Switzerland

${ }^{f}$ Department of Graphic Design and Engineering Projects, Bilbao Faculty of Engineering, University of the Basque Country (UPV/EHU), Bilbao 48103, Spain ${ }^{g}$ BCMaterials, Basque Center for Materials, Applications and Nanostructures, UPV/ EHU Science Park, 48940 Leioa, Spain 
<smiles>CCCCC(CC)COC(=O)CC(C(=O)OCC(CC)CCCC)S(=O)(=O)[O-]</smiles>

AOT

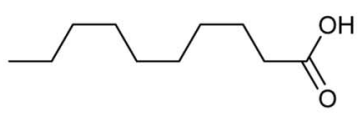

DA

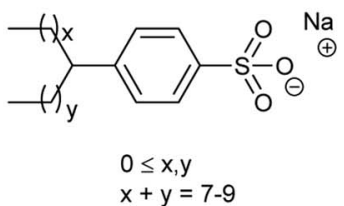

SDBS<smiles>CCC(C)C(c1ccc(S(=O)(=O)[O-])cc1)C(C)C</smiles>

SPS

(1)<smiles></smiles>

Bipolaron

Polaron

pair

Separated polarons

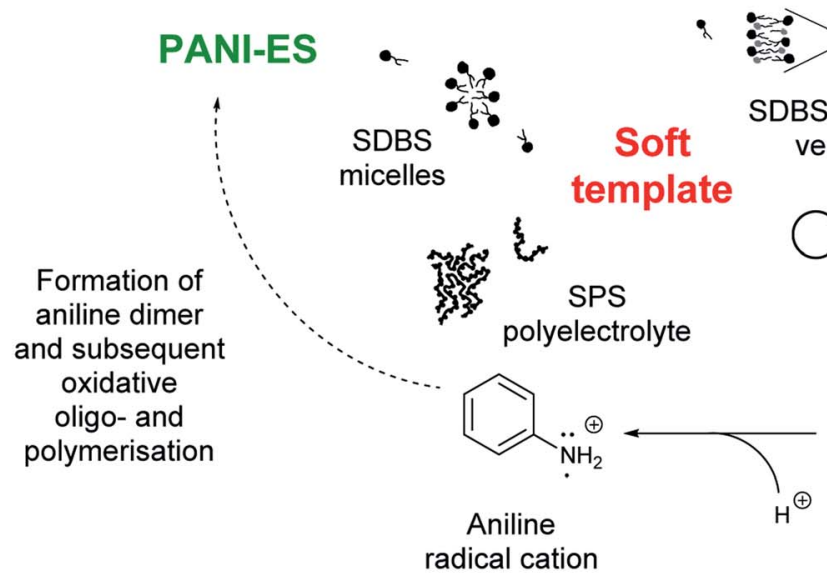

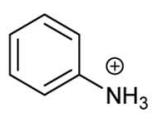

Anilinium $\left(p K_{\mathrm{a}}=4.6\right)$

Scheme 1 Schematic illustration of the horseradish peroxidase isoenzyme $\mathrm{C}(\mathrm{HRPC}) / \mathrm{H}_{2} \mathrm{O}_{2}$-catalysed oxidation of aniline at $\mathrm{pH}=4.3(0.1 \mathrm{M}$ $\mathrm{NaH}_{2} \mathrm{PO}_{4}+\mathrm{H}_{3} \mathrm{PO}_{4}$ ) and $T \approx 25^{\circ} \mathrm{C}$ in the presence of one of four different types of soft anionic templates: AOT vesicles, vesicles from a $1: 1$ molar mixture of sodium dodecylbenzenesulfonate (SDBS) and decanoic acid (DA), SDBS micelles, or sulfonated polystyrene (SPS) polyelectrolyte. All template molecules have one or more sulfonate groups and the reactions are initiated by adding aniline, $\mathrm{HRPC}$, and $\mathrm{H}_{2} \mathrm{O}_{2}$ to the template solutions or suspensions. Each reaction can be run under conditions which result in products that are rich in the conductive PANI-ES form. Chemical structures of the ideal PANI-ES repeating unit are shown in its diamagnetic bipolaron (1) and paramagnetic polaron forms (2). Mechanistically, HRPC is first oxidised by $\mathrm{H}_{2} \mathrm{O}_{2}$ in a two-electron oxidation. Oxidised HRPC then oxidises two aniline molecules in two oneelectron oxidations to yield two anilino radicals. After protonation to yield aniline radical cations, coupling reactions and further oxidation steps lead to the formation of PANI-ES repeating units (and other undesired side products). The templates "promote" desired PANI-ES product formation, act as counter ions $\left(\mathrm{A}^{-}\right)$, and prevent precipitation of the otherwise insoluble PANI-ES reaction products.

polyelectrolytes ${ }^{28-30}$ were used by different research groups with variation of the type of peroxidase and experimental conditions. In terms of template type, micelles formed from sodium dodecylbenzenesulfonate (SDBS) ${ }^{26,31}$ or other related amphiphiles, ${ }^{32}$ and vesicles from a 1:1 molar mixture of SDBS and decanoic acid (DA) ${ }^{33}$ or from $\mathrm{AOT}^{34-37}$ were found to be 
particularly promising. For the chemical structures, see Scheme 1. Although micelles and vesicles differ from polyelectrolytes, in the sense that they are polymolecular assemblies, which are constituted by amphiphilic molecules and only form above a certain critical concentration, both mentioned amphiphilic molecules, SDBS and AOT, have a sulfonate head group, and their micellar/vesicular self-assemblies are rich in sulfonate groups, similarly to the many sulfonate groups present in a single SPS molecule. In a broader sense, all three templates are soft, dynamic "sulfonate clusters". "Non-clustered" sulfonate groups do not act as templates. ${ }^{31,35}$

The aim of the first part of the work presented here was to make a direct comparison of the effect of four different soft sulfonate templates, which were used so far in the literature for the $\mathrm{HRP} / \mathrm{H}_{2} \mathrm{O}_{2}$-catalysed oxidation of aniline towards the formation of products which have a high content of PANI-ES repeating units. The templates used in our work were the polyelectrolyte SPS, micelles formed from SDBS, and vesicles formed either from a $1: 1\left(\mathrm{~mol} \mathrm{~mol}^{-1}\right)$ mixture of SDBS and DA or from AOT. All reactions were carried out at $\mathrm{pH}=4.3$ and at RT $\left(T \approx 25{ }^{\circ} \mathrm{C}\right)$, and for all reactions the same batch of HRP isoenzyme C (HRPC) was used. Furthermore, for each template type, the best template concentration was first determined. The reaction mixtures were analysed by in situ UV/vis/NIR, electron paramagnetic resonance (EPR), and Raman spectroscopy measurements, and the optimised, as-obtained solutions and dispersions were tested for their inkjet-printability. Finally, we investigated for the first time whether sulfated cellulose nanocrystals (abbreviated as CNCs), rod-like nanoscale particles which can be obtained upon a controlled hydrolysis of cellulose with sulfuric acid, ${ }^{38-40}$ could also be used as rigid template; and if this would be the case, how the performance of this rigid sulfate template would compare with the four chosen soft sulfonate templates.

The first part of this work is directly related to our previous work on the effect of different soft template types on the Trametes versicolor laccase (TvL)/ $\mathrm{O}_{2}$-catalysed oligomerisation of the linear para-NC-coupled aniline dimer PADPA ( $p$-aminodiphenylamine) to oligo(PADPA), carried out at $\mathrm{pH}=3.5$ and $T$ $\approx 25{ }^{\circ} \mathrm{C} .{ }^{41}$ This previous work was also aimed at obtaining products with a high content of PANI-ES repeating units. In the present work we wanted to know whether the template which appeared most ideal among the tested template types for the $\mathrm{PADPA} / \mathrm{TvL} / \mathrm{O}_{2}$ reaction, AOT vesicles, ${ }^{\mathbf{4 1}}$ is also the "best" one for the aniline/HRPC $/ \mathrm{H}_{2} \mathrm{O}_{2}$ reaction. Finally, we show first evidences on the use of CNC as rigid template for the synthesis of PANI-ES.

\section{Materials and methods}

\subsection{Commercial materials}

Horseradish peroxidase isoenzyme C (HRPC, product PEO-131, Grade I, $287 \mathrm{U} \mathrm{mg}^{-1}$, RZ $\geq 3$, lot number 2131616000) was from Toyobo Enzymes and aniline $\left(M=93.13 \mathrm{~g} \mathrm{~mol}^{-1} ; 99.8 \%\right)$ was from Acros Organics. Acetonitrile ( $\geq 99.5 \%)$. Docusate sodium salt (=bis(2-ethylhexyl) sulfosuccinate sodium salt, aerosol OT, AOT, $M=444.56 \mathrm{~g} \mathrm{~mol}^{-1}$, BioUltra $\geq 99.0 \%$ ), poly(sodium 4- styrenesulfonate) (SPS, average $M_{\mathrm{w}}=70000 \mathrm{~g} \mathrm{~mol}^{-1}$ ), microcrystalline cellulose ( $\mu$-cellulose) with a particle size of $20 \mu \mathrm{m}$, sodium phosphate monobasic $\left(\mathrm{NaH}_{2} \mathrm{PO}_{4}, \geq 99.0 \%\right)$, hydrogen peroxide (for analysis, $35 \mathrm{wt} \%$ solution in water, corresponding to $\left.11.4 \mathrm{~mol} \mathrm{~L}^{-1}\right)$, hydrochloric acid, ( $\mathrm{HCl}, \geq 37 \%$ ), sulfuric acid (95-98\%), pinacyanol chloride (2,2'-trimethinequinocyanine chloride, $M=388.9 \mathrm{~g} \mathrm{~mol}^{-1}$ ), and chloroform ( $\geq 99.0 \%$ ) were purchased from Sigma-Aldrich. Dodecylbenzenesulfonic acid sodium salt (hard type) (SDBS, $M=348.48 \mathrm{~g} \mathrm{~mol}^{-1}$; $>95 \%$ ) was from TCI Europe. ortho-Phosphoric acid $\left(\mathrm{H}_{3} \mathrm{PO}_{4}, 85 \%\right)$, decanoic acid (DA, $M=172.26 \mathrm{~g} \mathrm{~mol}^{-1}$; $\geq 99.0 \%$ ), and glycidyltrimethylammonium chloride (also known as epoxypropyltrimethylammonium chloride, EPTMAC) were purchased from Fluka. Deionised water prepared with a Millipore Synergy system was used for all experiments.

\subsection{Sulfated cellulose nanocrystal (CNC) synthesis and analysis}

Cellulose nanocrystals (CNCs) were obtained by hydrolysis of $20 \mathrm{~g}$ of $\mu$-cellulose using $400 \mathrm{~mL}$ of a $64 \mathrm{wt} \%$ sulfuric acid solution at $45{ }^{\circ} \mathrm{C}$ for $30 \mathrm{~min}$ under vigorous magnetic stirring (300 rpm). ${ }^{42}$ The reaction was quenched by adding $2 \mathrm{~L}$ of cold water and the remaining dispersion was centrifuged at $4000 \mathrm{rpm}$ with a Hettich Universal 320 table centrifuge for $10 \mathrm{~min}$ to remove excess aqueous acid. Nanosized cellulose was obtained after sonication (Vibracell Sonicator (Sonicsand Materials Inc., Danbury, CT)) at $40 \%$ output energy for $5 \mathrm{~min}$ using volumes of $50 \mathrm{~mL}$. The suspension was dialyzed against water for 7 days using a Visking dialysis membrane with a molecular weight cut off of 12 000-14000 Da from Medicell Membranes Ltd. to obtain an aqueous CNC dispersion of $\mathrm{pH}=$ 1.9 and 2 wt\%. If not indicated otherwise, CNCs stands for cellulose nanocrystals consisiting of sulfate groups (Scheme 2).

For control purposes, (sulfated) CNCs were rendered cationic through a reaction with EPTMAC. ${ }^{\mathbf{4 3 , 4 4}}$ Water-dispersed CNCs were desulfated using a $7 \mathrm{wt} \% \mathrm{NaOH}$ solution at $65{ }^{\circ} \mathrm{C}$ for $5 \mathrm{~h}$. After washing, cationization of the water-dispersed CNCs was carried out at $2 \mathrm{wt} \% \mathrm{NaOH}$ at RT followed by the addition of EPTMAC (1.554 $\mathrm{mmol} \mathrm{g}^{-1}$ with respect to CNC) at $65{ }^{\circ} \mathrm{C}^{.5}$ After $5 \mathrm{~h}$, the product was precipitated in ethanol and then washed several times with water. A final purification step using a Pur-A-

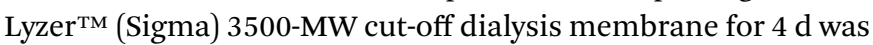
carried out. For the chemical structures of the repeating units of an anionic CNC chain and its cationic analogue, see Scheme 2.

The synthesised CNCs were characterised by X-ray powder diffraction (XRD) using a PANalytical Empyrean powder diffractometer in reflection mode with $\mathrm{Cu} \mathrm{K} \alpha$ radiation and operation at $45 \mathrm{kV}$ and $40 \mathrm{~mA}$. Attenuated total reflectance Fourier transform infrared spectroscopy (ATR-FTIR) measurements were performed on a Bruker Alpha FT-IR spectrometer equipped with diamond ATR optics. Elemental analysis was performed at the Microanalytic Laboratory of the Laboratory of Organic Chemistry at the Department of Chemistry and Applied Sciences (D-CHAB), ETH Zurich. Zeta-potential measurements of CNC suspensions at different $\mathrm{pH}$ values were performed on a Malvern Zetasizer Nano-ZS with a CNC concentration of 


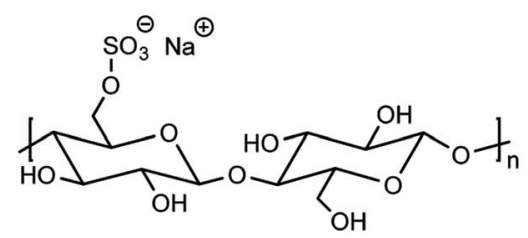

CNC (sulfated)

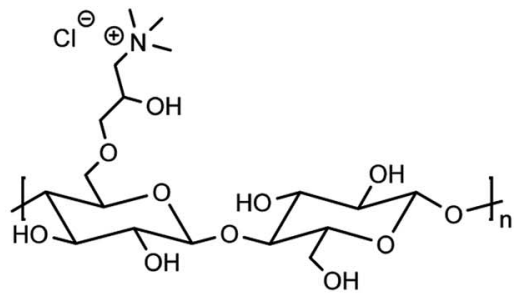

cationic analogue

Scheme 2 Chemical structures of the repeating units of a CNC chain and of a cationic analogue. For both structures the case of a single modification of the cellobiose repeating unit is shown.

$0.1 \mathrm{mg} \mathrm{mL} \mathrm{m}^{-1}$. The measurements were made at RT in a folded capillary cell (DTS1070). The thermal stability was assessed by thermal gravimetric analysis (with a Mettler Toledo TGA/ SDTA851e instrument) in alumina pans under nitrogen atmosphere by heating the samples from 25 to $1100{ }^{\circ} \mathrm{C}$ at $10{ }^{\circ} \mathrm{C} \mathrm{min}^{-1}$. The morphology of the CNC particles was determined by transmission electron microscopy (TEM) with a Philips CM120 Biofilter apparatus with a STEM module at an acceleration voltage of $120 \mathrm{kV}$. A droplet of a $0.1 \mathrm{wt} \%$ suspension of CNCs in water was deposited onto carbon-coated grids and then negatively stained with $1 \%(\mathrm{w} / \mathrm{v})$ uranyl acetate $\left(\mathrm{UO}_{2}\left(\mathrm{CH}_{3} \mathrm{COO}\right)_{2}\right)$ for $1 \mathrm{~min}$. Scanning electron microscopy (SEM) analyses were performed on a LEO Gemini 1530 instrument (from Zeiss).

\subsection{Preparation of stock solutions and suspensions}

2.3.1. $" \mathrm{pH}=4.3$ solution". A $\mathrm{pH}=4.3$ solution $(0.1 \mathrm{M})$ was prepared at $\mathrm{RT}\left(T \approx 25{ }^{\circ} \mathrm{C}\right)$ by first dissolving $0.1 \mathrm{~mol}$ of $\mathrm{NaH}_{2} \mathrm{PO}_{4}$ in deionised water to yield a total volume of $1 \mathrm{~L}$, followed by adjustment of the $\mathrm{pH}$ value with $1 \mathrm{M} \mathrm{H}_{3} \mathrm{PO}_{4}$ until $\mathrm{pH}=$ 4.3. This " $\mathrm{pH}=4.3$ solution" was used for the preparation of all template solutions and suspensions and for all polymerisation reactions.

2.3.2. Aniline stock solution. A $40 \mathrm{mM}$ aniline stock solution was prepared by dissolving $105 \mu \mathrm{L}$ of aniline $(1.15 \mathrm{mmol})$ in $28.59 \mathrm{~mL}$ of the $\mathrm{pH}=4.3$ solution, followed by adjustment of the $\mathrm{pH}$ value to 4.3 with a $\mathrm{HCl}$ solution $\left(0.12 \mathrm{~g} \mathrm{HCl} \mathrm{mL}^{-1}\right)$. This aniline stock solution was stored in a refrigerator at $T \approx 5{ }^{\circ} \mathrm{C}$ and used within three weeks.

2.3.3. HRPC stock solution. A HRPC stock solution $(\approx 70$ $\mu \mathrm{M}$ ) was prepared by dissolving $3.4 \mathrm{mg}$ of HRPC powder in $1 \mathrm{~mL}$ deionised water. The HRPC concentration in this solution was determined spectrophotometrically by using $\varepsilon_{403}=1.02 \times$ $10^{5} \mathrm{M}^{-1} \mathrm{~cm}^{-1}$ as molar absorbance, ${ }^{46}$ yielding $67.7 \mu \mathrm{M}$. This enzyme stock solution was stored at $T \approx 5{ }^{\circ} \mathrm{C}$ and used within one month.

2.3.4. $\mathrm{H}_{2} \mathrm{O}_{2}$ stock solution. A hydrogen peroxide stock solution (200 $\mathrm{mM}$ ) was prepared by dissolving $17.5 \mu \mathrm{L}$ hydrogen peroxide solution (35 wt\%) in $982.5 \mu \mathrm{L}$ deionized water. This solution was freshly prepared every day.

2.3.5. AOT vesicle stock suspension. A vesicle suspension of $20 \mathrm{mM}$ AOT consisting of mainly unilamellar vesicles with average diameters of about $100 \mathrm{~nm}$ was prepared in the same way as described before. ${ }^{41}$ The only difference was the use of the $\mathrm{pH}=4.3$ solution instead of the $\mathrm{pH}=3.5$ solution. The critical concentration for AOT vesicle formation (cvc) is about $0.4 \mathrm{mM}^{34}$ The vesicle suspension was stored at RT and used within three weeks.

2.3.6. SDBS/DA (1 : 1) vesicle stock suspension. A vesicle suspension consisting of equimolar amounts of SDBS and DA, each $20 \mathrm{mM}$ and mainly unilamellar vesicles of about $100 \mathrm{~nm}$ was prepared in the same way as described before by using the $\mathrm{pH}=4.3$ solution instead of the $\mathrm{pH}=3.5$ solution, with cvc $\approx$ $0.4 \mathrm{mM}^{41}$ The vesicle suspension was stored at RT and used within three weeks.

2.3.7. SDBS micelle stock solution. A $20 \mathrm{mM}$ SDBS micellar solution was prepared at RT by dissolving $0.1394 \mathrm{~g}(0.4 \mathrm{mmol})$ of SDBS in $20 \mathrm{~mL}$ of the $\mathrm{pH}=4.3$ solution. The micellar solution was stored at RT and used within one month. With pinacyanol chloride the critical concentration for SDBS micelle formation (cmc) was determined in the same way as described before. ${ }^{\mathbf{4 1}}$ The value obtained in the $\mathrm{pH}=4.3$ solution (data not shown) was the same as the one determined previously for the $\mathrm{pH}=3.5$ solution $(\mathrm{cmc} \approx 0.3 \mathrm{mM}) .^{41}$

2.3.8. SPS polyelectrolyte stock solution. A SPS polyelectrolyte solution with $20 \mathrm{mM}$ SPS repeating unit (r.u.) was prepared as described before, by using the $\mathrm{pH}=4.3$ solution instead of the $\mathrm{pH}=3.5$ solution. ${ }^{41}$ The polyelectrolyte solution was stored at RT and used within one month.

2.3.9. Cellulose nanocrystals (CNC) stock suspension. A $2 \mathrm{wt} \%$ suspension of $\mathrm{CNC}$ was prepared in a $0.01 \mathrm{M} \mathrm{NaH}_{2} \mathrm{PO}_{4} /$ $\mathrm{H}_{3} \mathrm{PO}_{4}$ solution which was obtained by tenfold dilution of the $\mathrm{pH}=4.3$ solution with deionized water.

\subsection{Preparation and analysis of reaction mixtures containing soft templates}

2.4.1. Reaction mixture preparation. All reactions were carried out inside $2.0 \mathrm{~mL}$ Eppendorf tubes at RT. Defined volumes of the different separately prepared stock solutions or suspensions were added and mixed in the following sequence: (a) $\mathrm{pH}=4.3$ solution, (b) template stock solution or suspension, (c) aniline stock solution, (d) HRPC stock solution, and (e) $\mathrm{H}_{2} \mathrm{O}_{2}$ stock solution. The total reaction volume was always $500.15 \mu \mathrm{L}$. After mixing by gentle agitation 
(set to reaction time $t=0$ ) and closing the tubes with the cap, the reaction mixtures were left standing at RT until they were analysed by one of the spectrophotometric methods used. In the case of the reaction mixtures containing SPS polyelectrolyte, about 5 min agitation was necessary for obtaining reproducible results. For each template and the conditions which we considered optimal and ideal for a direct comparison of the effect of the templates (see below), the different volumes of the stock solutions and suspensions are listed in Table 1.

2.4.2. In situ UV/vis/NIR, EPR, and Raman spectroscopy measurements. All in situ spectroscopy measurements were carried out at RT in the same way as described before. ${ }^{41}$ For the UV/vis/NIR and EPR measurements, $0.3 \mathrm{~mL}$ of the reaction mixtures were analysed with a JASCO V-670 and a Bruker EMX X-band spectrometer, respectively. For the Raman measurements, a DXR Raman microscope (from Thermo Scientific) was used, and drops of the reaction mixtures with volumes of a few $\mu \mathrm{L}$ were analysed.

2.4.3. Quantification of unreacted aniline present in the reaction mixtures. The concentration of unreacted aniline in the reaction mixtures after a reaction time $t=24 \mathrm{~h}$ was determined spectrophotometrically, as described before. ${ }^{35}$ First, $30 \mu \mathrm{L}$ of the reaction mixture was added to $1470 \mu \mathrm{L}$ acetonitrile which was placed inside a $2.0 \mathrm{~mL}$ Eppendorf tube. After centrifugation with an Eppendorf centrifuge $5415 \mathrm{D}$ to remove the reaction products, the UV/vis absorption spectrum of the supernatant solution was recorded with a JASCO V-670 spectrophotometer by using a quartz cell with a path length of $l=0.1 \mathrm{~cm}$. The same analysis was carried out for the reaction mixtures at $t=0 \mathrm{~h}$, i.e. immediately before adding $\mathrm{H}_{2} \mathrm{O}_{2}$ for starting the reaction. Second, as reference measurement, the same procedure was applied to a reaction mixture which did not contain aniline. Third, the measured reference spectrum was subtracted from the spectrum obtained from the reaction mixture, and $\Delta A_{238}(t=24 \mathrm{~h}$ or $t=$ $0 \mathrm{~h}$ ) the difference in absorbance at $238 \mathrm{~nm}$, was determined. With $\Delta A_{238}(t=24 \mathrm{~h})$, the concentration of aniline in the acetonitrile solution (and in the reaction mixture) could be determined by taking into account $\varepsilon_{238}$ (aniline) $=10600 \pm$ $300 \mathrm{M}^{-1} \mathrm{~cm}^{-1}$ as molar absorbance. ${ }^{35}$ The percentile aniline conversion was calculated for each reaction mixture by comparing $\Delta A_{238}(t=24 \mathrm{~h})$ with $\Delta A_{238}(t=0 \mathrm{~h})$, see Fig. S-1-S3, ESI.†

2.4.4. Test of inkjet-printability. The as-obtained reaction mixtures were used as ink in a thermal desktop inkjet printer with printing on ordinary white paper, as described before. ${ }^{41}$

\subsection{Preparation and analysis of reaction mixtures containing rigid $\mathrm{CNC}$ templates}

2.5.1. Reaction mixture preparation. The reactions with CNCs as templates (and the corresponding controls without CNCs) were carried out in a similar way as described for the reactions in the presence of soft templates, again using $2.0 \mathrm{~mL}$ Eppendorf tubes (see Section 2.4.1). Defined volumes of the following stock solutions were added and mixed in the indicated sequence: (a) $\mathrm{pH}=4.3$ solution diluted 1:1 with deionised water (0.05 $\left.\mathrm{M} \mathrm{NaH}_{2} \mathrm{PO}_{4}+\mathrm{H}_{3} \mathrm{PO}_{4}\right)$, (b) CNC stock suspension, (c) aniline stock solution, (d) HRPC stock solution diluted with water 1 : $9\left(0.34 \mathrm{mg}\right.$ HRPC $\left.\mathrm{mL}^{-1}, 6.67 \mu \mathrm{M}\right)$, and (e) $\mathrm{H}_{2} \mathrm{O}_{2}$ stock solution diluted 1 : 9 with water $\left(20 \mathrm{mM} \mathrm{H}_{2} \mathrm{O}_{2}\right)$. The total volume was $400 \mu \mathrm{L}$. The volumes used for the "optimal" conditions are given in Table 2 . For other reaction mixtures prepared and analysed in this work, see Table S-1, ESI. $\dagger$

2.5.2. Reaction product analysis. In situ UV/vis/NIR and EPR spectra were recorded in the same way as described for the reaction mixtures with the soft templates, as well as the quantification of unreacted aniline see Section 2.4.2 and 2.4.3. High resolution scanning electron microscopy (HR-SEM), FTIR and DSC analyses were carried out as described in Section 2.2. For the HR-SEM measurements, the CNC/PANI-ES suspension (rxn \# 3, prepared in sodium dihydrogen phosphate solution) were washed by centrifugation two times with deionised water at $10000 \mathrm{rpm}$ for $10 \mathrm{~min}$ to remove excess salt. For the FTIR and DSC measurements, the suspension was allowed to dry at RT for $48 \mathrm{~h}$, followed by vacuum drying at $60^{\circ} \mathrm{C}$ for $24 \mathrm{~h}$.

Table 1 Details of the preparation of the different reaction mixtures in the presence of soft templates ( $500.15 \mu \mathrm{L}$ total volume). The pH value of the reaction mixtures was kept constant at $\mathrm{pH}=4.3\left(0.1 \mathrm{M} \mathrm{NaH}_{2} \mathrm{PO}_{4}+\mathrm{H}_{3} \mathrm{PO}_{4}\right)$. For all reaction mixtures, the initial concentration of aniline was $4.0 \mathrm{mM}$, the HRPC concentration $0.92 \mu \mathrm{M}$ and all reactions were initiated with $4.5 \mathrm{mM} \mathrm{H}_{2} \mathrm{O}_{2}$. For finding the optimal template molecule concentrations, the ratio of the volume of the $\mathrm{pH}=4.3$ solution to the volume of the template stock solution or suspension was varied while keeping their total volume constant $(432.2 \mu \mathrm{L})$. The volumes given in the table are the ones considered as optimal for a direct comparison of the effect of the templates. The concentrations given in parenthesis are the initial concentrations in the reaction mixtures, see text for details

\begin{tabular}{|c|c|c|c|c|c|}
\hline Template type & $\begin{array}{l}\mathrm{pH}=4.3 \text { solution }^{a} \\
(\mu \mathrm{L})\end{array}$ & $\begin{array}{l}\text { Template stock solution or } \\
\text { suspension }^{b}(\mu \mathrm{L})\end{array}$ & $\begin{array}{l}\text { Aniline stock solution }{ }^{c} \\
(\mu \mathrm{L})\end{array}$ & $\begin{array}{l}\text { HRPC stock solution }{ }^{d} \\
(\mu \mathrm{L})\end{array}$ & $\begin{array}{l}\mathrm{H}_{2} \mathrm{O}_{2} \text { stock solution } \\
(\mu \mathrm{L})\end{array}$ \\
\hline AOT vesicles & 357.2 & $75.0(\rightarrow 3.0 \mathrm{mM})$ & $49.9(\rightarrow 4.0 \mathrm{mM})$ & $6.8(\rightarrow 0.92 \mu \mathrm{M})$ & $11.3(\rightarrow 4.5 \mathrm{mM})$ \\
\hline SDBS micelles & 374.7 & $57.5(\rightarrow 2.3 \mathrm{mM})$ & & & \\
\hline SPS polyelectrolyte & 374.7 & $57.5(\rightarrow 2.3 \mathrm{mM}$ r.u. $)$ & & & \\
\hline
\end{tabular}

${ }^{a} \mathrm{pH}=4.3$ solution: $\left[\mathrm{NaH}_{2} \mathrm{PO}_{4}\right]+\left[\mathrm{H}_{3} \mathrm{PO}_{4}\right]=0.1$ M. ${ }^{b} 20 \mathrm{mM}$ AOT; or $20 \mathrm{mM}$ SDBS and $20 \mathrm{mM}$ DA; or $20 \mathrm{mM}$ SDBS; or $20 \mathrm{mM}$ SPS r.u. in pH $=4.3$ solution. ${ }^{c} 40 \mathrm{mM}$ aniline in $\mathrm{pH}=4.3$ solution (adjusted to $\mathrm{pH}=4.3$ with $\mathrm{HCl}$ ). ${ }^{d} 67.7 \mu \mathrm{M}$ HRPC (dissolved in deionised water). ${ }^{e} 200 \mathrm{mM} \mathrm{H}_{2} \mathrm{O}_{2}$ (dissolved in deionised water). 
Table 2 Details of the preparation of the "optimal" reaction mixture with CNCs as rigid templates (400 $\mu$ L total volume), abbreviated as "rxn \# 3", see below. The concentrations given in parenthesis are the initial concentrations in the reaction mixture at the start of the reaction

\begin{tabular}{llll}
\hline Template type & Diluted pH 4.3 solution $^{a}(\mu \mathrm{L})$ CNC stock suspension ${ }^{b}(\mu \mathrm{L})$ solution $^{c}(\mu \mathrm{L})$ & $\begin{array}{l}\text { AnRPC stock } \\
\text { solution }^{d}(\mu \mathrm{L})\end{array}$ & $\begin{array}{l}\mathrm{H}_{2} \mathrm{O}_{2} \text { stock } \\
\text { solution }^{e}(\mu \mathrm{L})\end{array}$ \\
\hline CNC: sulfated cellulose & 169.9 & $92.8(\rightarrow 0.46 \mathrm{wt} \%)$ & $80.0(\rightarrow 8.0 \mathrm{mM}) 21.3(\rightarrow 0.36 \mu \mathrm{M}) 36.0(\rightarrow 1.8 \mathrm{mM})$
\end{tabular}

nanocrystals

${ }^{a}\left[\mathrm{NaH}_{2} \mathrm{PO}_{4}\right]+\left[\mathrm{H}_{3} \mathrm{PO}_{4}\right]=0.05 \mathrm{M}^{b}{ }^{b} 2 \mathrm{wt} \% .^{c} 40 \mathrm{mM}$ aniline in $\mathrm{pH}=4.3$ solution (adjusted to $\left.\mathrm{pH}=4.3\right)$ with $\mathrm{HCl} .{ }^{d} 6.67 \mu \mathrm{M} \mathrm{HRPC}($ dissolved in deionised water). ${ }^{e} 20 \mathrm{mM} \mathrm{H}_{2} \mathrm{O}_{2}$ (dissolved in deionised water).

\section{Results and discussion}

\subsection{Specification of "optimal reaction conditions" and criteria used for template comparison}

For any type of reaction optimisation, one has to specify defining criteria. Direct comparison of the influence of a single component of a complex reaction mixture, the template in our case, requires keeping all other components in the reaction mixtures with identical concentrations at the beginning. Initial conditions were selected as follows: $\mathrm{pH}=4.3\left(\left[\mathrm{NaH}_{2} \mathrm{PO}_{4}\right]+\right.$ $\left.\left[\mathrm{H}_{3} \mathrm{PO}_{4}\right]=0.1 \mathrm{M}\right)$, [aniline $]=4.0 \mathrm{mM},[\mathrm{HRPC}]=0.92 \mu \mathrm{M}$, and $\left[\mathrm{H}_{2} \mathrm{O}_{2}\right]=4.5 \mathrm{mM}$. These conditions originate from previous work with AOT vesicles where the reaction was found to be optimal at $[\mathrm{AOT}]=3.0 \mathrm{mM} .^{35}$ Under these conditions, the reaction can be followed by in situ UV/vis/NIR absorption measurements with cells of path length $l=0.1 \mathrm{~cm}$, requiring no dilution of the mixture until equilibrium is reached; the absorbance $\left(A_{\lambda}\right)$ between 250 and $1200 \mathrm{~nm}$ never exceeds $A_{\lambda} \approx$ 1.5 and therefore remains in the linear $A v s$. concentration range of the spectrophotometer used. For a comparison of the effects of the soft templates used, the above mentioned "standard concentrations" were used. In the case of CNC, however, modifications were necessary since the final reaction mixtures did not show the desired properties in terms of colour and physical state, see later Section 3.3.

The criteria for the optimal conditions with the soft templates were as follows. The products obtained should have (i) high absorption at $1000 \mathrm{~nm}\left(A_{1000}\right)$ and a band centred around $\approx 420 \mathrm{~nm}$, which both is indicative for the formation of PANI-ES (Scheme 1); ${ }^{19,47}$ (ii) low absorption at 500-600 nm (absence of unwanted branching or phenazine formation); ;5,48 (iii) an EPR spectrum, indicative for the presence of unpaired electrons; ${ }^{\mathbf{1 , 4 9 , 5 0}}$ (iv) Raman bands at $\approx \mathbf{1 3 2 0}-1380 \mathrm{~cm}^{-1}$ assigned to polaronic structures; $;^{1,51,52}$ and the as-obtained reaction mixture must be (iv) an inkjet-printable, colloidally stable solution or dispersion.

\subsection{Comparison of AOT vesicles, SDBS/DA (1:1) vesicles, SDBS micelles, and SPS polyelectrolyte as soft templates}

3.2.1. Optimal reaction conditions. Based on a variation of template molecule concentration with initial aniline, HRPC, and $\mathrm{H}_{2} \mathrm{O}_{2}$ concentrations identical, the optimal conditions determined for each reaction mixture are summarized in Table 1. These optimal conditions are derived from a series of in situ UV/vis/NIR absorption measurements carried out after a reaction time of $24 \mathrm{~h}$ at RT and by considering $A_{\approx 1000}$ and $A_{1000} / A_{500}$. Desired conditions were those where both values were high and no precipitation occurred. Data for the different reaction mixtures containing various amounts of SDBS/DA (1:1) vesicles, SDBS micelles, or SPS polyelectrolyte are given in Fig. S-4, ESI. $\dagger$

3.2.2. In situ recorded UV/vis/NIR and EPR spectra and aniline conversion. For each sulfonate template used the UV/ vis/NIR and EPR spectra of the reaction mixtures prepared at their optimal conditions were measured after a reaction time of $24 \mathrm{~h}$ at RT, see Fig. 1-4. The reproducibility of the reaction is illustrated by the variation in the spectra by three runs carried out under identical conditions for each template, as described in Table 1. For all four soft templates reproducibility was excellent. Prolonged storage of the reaction mixtures for up to 7 $\mathrm{d}$ indicated that the reactions still proceeded to some extend without changing the main features of the spectra, see Fig. S-5, ESI. $\dagger$ The UV/vis/NIR spectrum measured for the reaction mixture containing AOT vesicles is in good agreement with the spectra we obtained in our previous investigations of this system. ${ }^{35,37}$

Although all reaction mixtures turned dark green with very similar product spectra for all four templates, significant differences among the absorption spectra still exist. With SPS polyelectrolyte, for example, the absorption maximum in the vis/NIR region is found at $\approx 830 \mathrm{~nm}$ (Fig. $4 \mathrm{~A}$ ), while with the two vesicle systems it is at $\approx 1010 \mathrm{~nm}$ (AOT, Fig. $1 \mathrm{~A}$ ) or $\approx 1060 \mathrm{~nm}$ (SDBS : DA (1:1), Fig. 2A). With SDBS micelles, the band is very broad, ranging from $\approx 800 \mathrm{~nm}$ to $\approx 1100 \mathrm{~nm}$ (Fig. 3A). Moreover, with SDBS micelles, the EPR spectrum is rather broad, indicating that a large fraction of the radicals is present in a less ordered state, compared to the products formed in the other three systems. The absorbance values at $1000 \mathrm{~nm}\left(A_{1000}\right.$, Fig. 4A) are correlated to the integrals of the EPR spectrum (Fig. 5B). For products obtained with AOT vesicles, both values of $A_{1000}$ and EPR signal integral (i.e., radical content) were highest, while both of these values were lowest for the products obtained with SDBS micelles (Fig. 5A and B). If $A_{500}$ is taken into account as well (Fig. 5C), it is lowest for the SDBS micelle system and highest for the AOT vesicle system. This may be due to the slight turbidity of the AOT vesicle suspension compared to the SDBS micellar solution. In terms of the $A_{1000} / A_{500}$ ratio, the products obtained with SDBS/DA (1:1) vesicles give the highest value, higher than for the products obtained with AOT vesicles or SDBS micelles (Fig. 5D). 


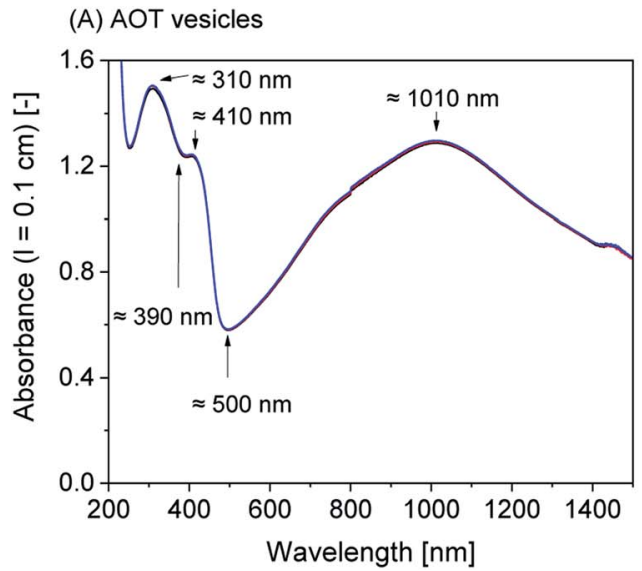

(B) AOT vesicles

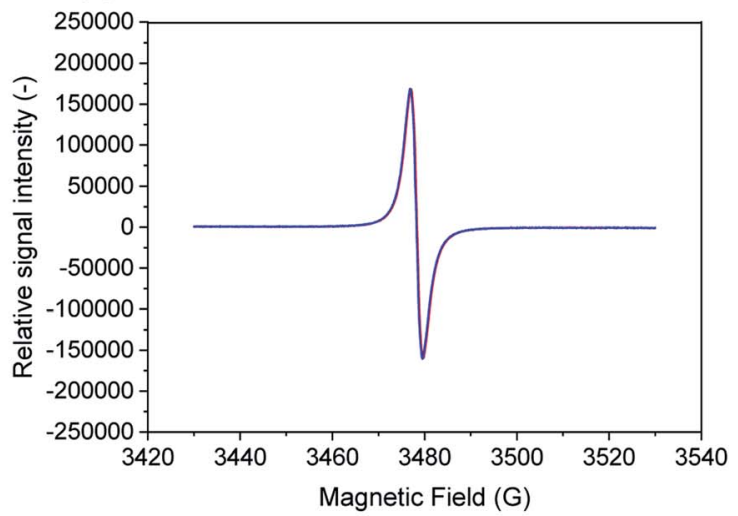

Fig. $1 \mathrm{UV} / \mathrm{vis} / \mathrm{NIR}(\mathrm{A})$ and EPR (B) spectra of the reaction mixtures recorded after $t=24 \mathrm{~h}$ at $T \approx 25^{\circ} \mathrm{C}$ in the presence of AOT vesicles as templates with the following initial conditions: $[A O T]=3.0 \mathrm{mM}$, [aniline] $=4.0 \mathrm{mM},[\mathrm{HRPC}]=0.92 \mu \mathrm{M},\left[\mathrm{H}_{2} \mathrm{O}_{2}\right]=4.5 \mathrm{mM}, \mathrm{pH}=4.3 \mathrm{solution}$. Three spectra are shown as obtained from three separate reactions to illustrate the reproducibility.

The highest conversion degree of aniline after $24 \mathrm{~h}$ was determined for the reaction with AOT vesicles (90\%). For the reactions with SPS polyelectrolyte (66\%), SDBS/DA (1:1) vesicles (64\%), and SDBS micelles (52\%), the aniline conversion was lower, see Fig. 5E. According to the EPR integral normalised by the extent of aniline conversion, products obtained with SDBS/ DA $(1: 1)$ vesicles give the highest relative radical content, followed by products from AOT vesicles (Fig. 5F).

Based on the UV/vis/NIR and EPR measurements and on the conversion degree of aniline, we conclude that the use of AOT or SDBS/DA $(1: 1)$ vesicles provides advantages in terms of desired product properties (EPR intensity and $A_{1000} / A_{500}$ ratio) over SDBS micelles or SPS polyelectrolyte. Since aniline conversion in the presence of SDBS micelles is rather limited, these micellar templates appear the least attractive from an economic point of view.

3.2.3. In situ recorded Raman spectra. For each soft sulfonate template used, the Raman spectrum of the reaction mixtures prepared at their optimal conditions was measured after a reaction time of $4 \mathrm{~d}$ at RT, see Fig. 6 . The reproducibility of the reaction was again illustrated by Raman spectroscopy, after running three reactions of the same initial composition for each template. The spectra of the three product mixtures resemble each other, and they are also in good agreement with the spectra measured after a reaction time of $15 \mathrm{~d}$ (Fig. S-8, ESI $\uparrow$ ). Intensity differences among the spectra recorded for the three reaction runs in the presence of the same template are most probably due to the statistical nature of in situ Raman measurements that depend on the local concentration of the polymer molecules at the drop surface. Moreover, independent from the type of soft template used, the Raman spectra are very similar. Nevertheless, small differences are still seen in the relative band intensities.

All spectra confirm the presence of conductive PANI-ES units in the final products. The bands which are characteristic for PANI$E S$ are observed at $1605-1598 \mathrm{~cm}^{-1}(\mathrm{C}=\mathrm{C}$ and $\mathrm{C}-\mathrm{C}$ stretching
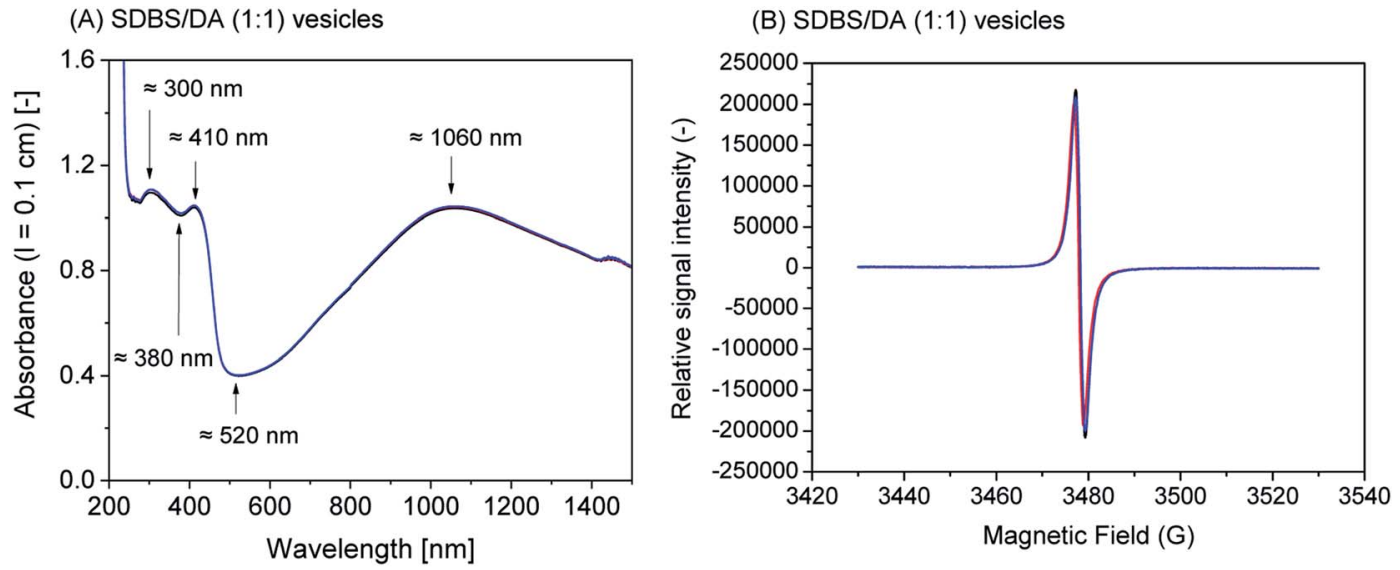

Fig. $2 \mathrm{UV} / \mathrm{vis} / \mathrm{NIR}(\mathrm{A})$ and EPR (B) spectra of the reaction mixtures recorded after $t=24 \mathrm{~h}$ at $T \approx 25^{\circ} \mathrm{C}$ in the presence of SDBS/DA (1: 1$)$ vesicles as templates with the following initial conditions: $[\mathrm{SDBS}]=[\mathrm{DA}]=2.1 \mathrm{mM}$, [aniline] $=4.0 \mathrm{mM},[\mathrm{HRPC}]=0.92 \mu \mathrm{M},\left[\mathrm{H}_{2} \mathrm{O}_{2}\right]=4.5 \mathrm{mM}, \mathrm{pH}=4.3$ solution. Three spectra are shown as obtained from three separate reactions to illustrate the reproducibility. 

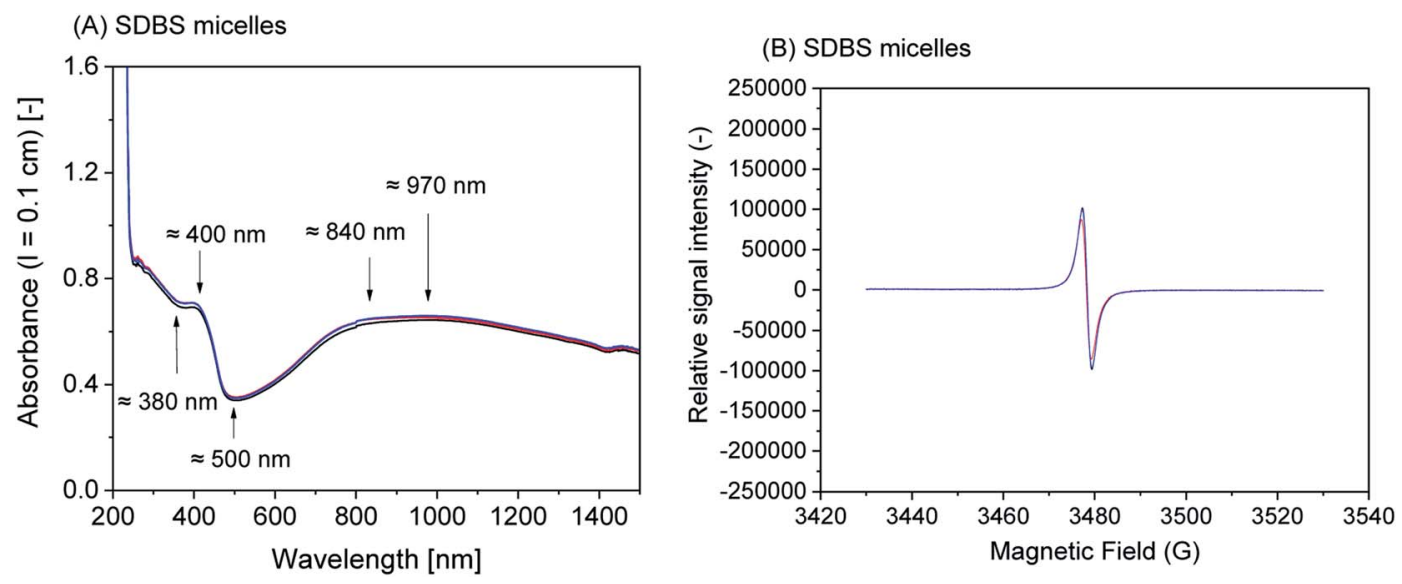

Fig. $3 \mathrm{UV} / \mathrm{vis} / \mathrm{NIR}(\mathrm{A})$ and EPR (B) spectra of the reaction mixtures recorded after $t=24 \mathrm{~h}$ at $T \approx 25^{\circ} \mathrm{C}$ in the presence of SDBS micelles as templates with the following initial conditions: $[\mathrm{SDBS}]=2.3 \mathrm{mM}$, [aniline] $=4.0 \mathrm{mM}$, [HRPC] $=0.92 \mu \mathrm{M}\left[\mathrm{H}_{2} \mathrm{O}_{2}\right]=4.5 \mathrm{mM}, \mathrm{pH}=4.3 \mathrm{solution}$. Three spectra are shown as obtained from three separate reactions to illustrate the reproducibility.

vibrations of quinonoid (Q) and semiquinonoid (SQ) rings, $\nu(\mathrm{C}=\mathrm{C})_{\mathrm{Q}}$ and $\left.\nu(\mathrm{C}-\mathrm{C})_{\mathrm{SQ}}\right), 1515-1513 \mathrm{~cm}^{-1}(\mathrm{~N}-\mathrm{H}$ bending vibration, $\delta(\mathrm{N}-\mathrm{H})$, in SQ units), $1344-1339 \mathrm{~cm}^{-1}$ with a shoulder at $\approx 1360 \mathrm{~cm}^{-1}\left(\mathrm{C}-\mathrm{N}^{++}\right.$stretching vibrations in polaronic $\mathrm{SQ}$ structures, $\left.\nu\left(\mathrm{C}-\mathrm{N}^{++}\right)_{\mathrm{SQ}}\right), 1267-1259 \mathrm{~cm}^{-1}$ and $1233-1225 \mathrm{~cm}^{-1}$ (C-N stretching in benzenoid (B) rings, $\left.\nu(\mathrm{C}-\mathrm{N})_{\mathrm{B}}\right)$, 1183$1178 \mathrm{~cm}^{-1}(\mathrm{C}-\mathrm{H}$ bending in-plane vibrations of $\mathrm{B}$ rings, $\delta(\mathrm{C}-$ $\left.\mathrm{H})_{\mathrm{B}}\right), 824-815 \mathrm{~cm}^{-1}$ (C-H wagging out-of-plane in polaronic structure/Q ring deformation in bipolaronic structure), and at $\approx 730 \mathrm{~cm}^{-1}$ (C-C ring deformation vibration, out-of-plane, in polaronic/bipolaronic PANI-ES structures). ${ }^{51,53}$ The band observed at $616-613 \mathrm{~cm}^{-1}$ is due to $\mathrm{B}$ ring deformation (inplane) of PANI-ES polaronic structure ${ }^{51,53}$ combined with $\delta\left(\mathrm{SO}_{2}\right)$ vibrations in sulfonate $\left(-\mathrm{SO}_{3}{ }^{-}\right)$groups of all template molecules. ${ }^{54,55}$

The coexistence of the two bands attributed to $\nu\left(\mathrm{C}-\mathrm{N}^{\circ+}\right)$ vibrations, observed at $\approx 1340 \mathrm{~cm}^{-1}$ and $1360 \mathrm{~cm}^{-1}$, indicates two types of polarons present in the PANIs prepared enzymatically with different templates ('́irić-Marjanović et al. $(2008)^{51}$ and references therein). The very strong band at $1340 \mathrm{~cm}^{-1}$ is attributed to highly delocalised polaronic sites, while the shoulder at higher wavenumber, $\approx 1360 \mathrm{~cm}^{-1}$, corresponds to localised polarons (with possible contribution of $\nu\left(\mathrm{C}-\mathrm{N}^{+}\right)$vibrations in substituted $N$-phenylphenazine-type structural units). ${ }^{51,56,57}$ This means that the distribution of SQ radical cations (polarons) in PANIs is not uniform, and that delocalised polarons prevail. Similar spectral characteristic was found in the case of oligo-PADPA) produced with HRPC in the presence of AOT vesicles as templates, ${ }^{47}$ however, in that case the wavenumbers and the intensity ratio of the two $\nu\left(\mathrm{C}-\mathrm{N}^{*+}\right)_{\mathrm{SQ}}$ bands were different: the Raman spectra of the final oligo(PADPA) products (at $t=3 \mathrm{~d}$ and $t$ $=19 \mathrm{~d})$ exhibited a strong $\nu\left(\mathrm{C}-\mathrm{N}^{*}\right)_{\mathrm{SQ}}$ band at higher wavelength $\left(\approx 1350 \mathrm{~cm}^{-1}\right)$, attributed to polarons with low delocalisation, and the weaker shoulder at lower wavelength (at $\approx 1330 \mathrm{~cm}^{-1}$ ) that corresponds to highly delocalised polarons, see Fig. S2 in the ESI $\dagger$ of Luginbühl et al. (2017). ${ }^{48}$
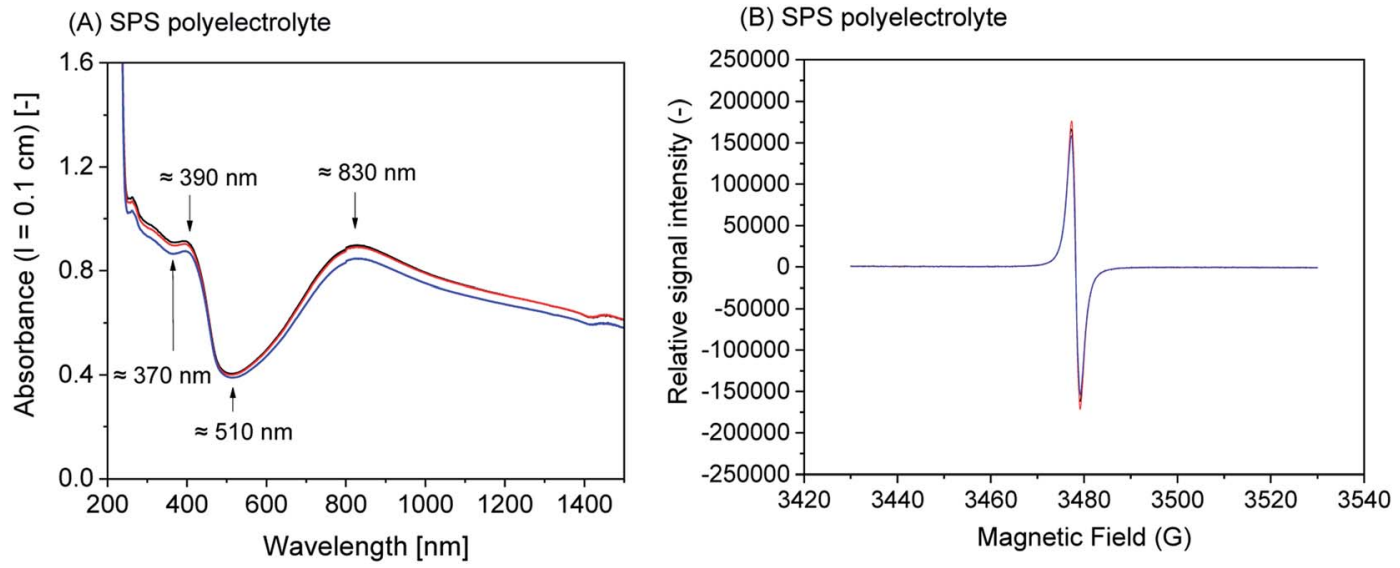

Fig. $4 \mathrm{UV} /$ vis/NIR (A) and EPR (B) spectra of the reaction mixtures recorded after $t=24 \mathrm{~h}$ at $T \approx 25^{\circ} \mathrm{C}$ in the presence of SPS polyelectrolyte as templates with the following initial conditions: [SPS r.u.] $=2.3 \mathrm{mM}$, [aniline] $=4.0 \mathrm{mM}$, [HRPC] $=0.92 \mu \mathrm{M},\left[\mathrm{H}_{2} \mathrm{O}_{2}\right]=4.5 \mathrm{mM}, \mathrm{pH}=4.3 \mathrm{solution}$. Three spectra are shown as obtained from three separate reactions to illustrate the reproducibility. 

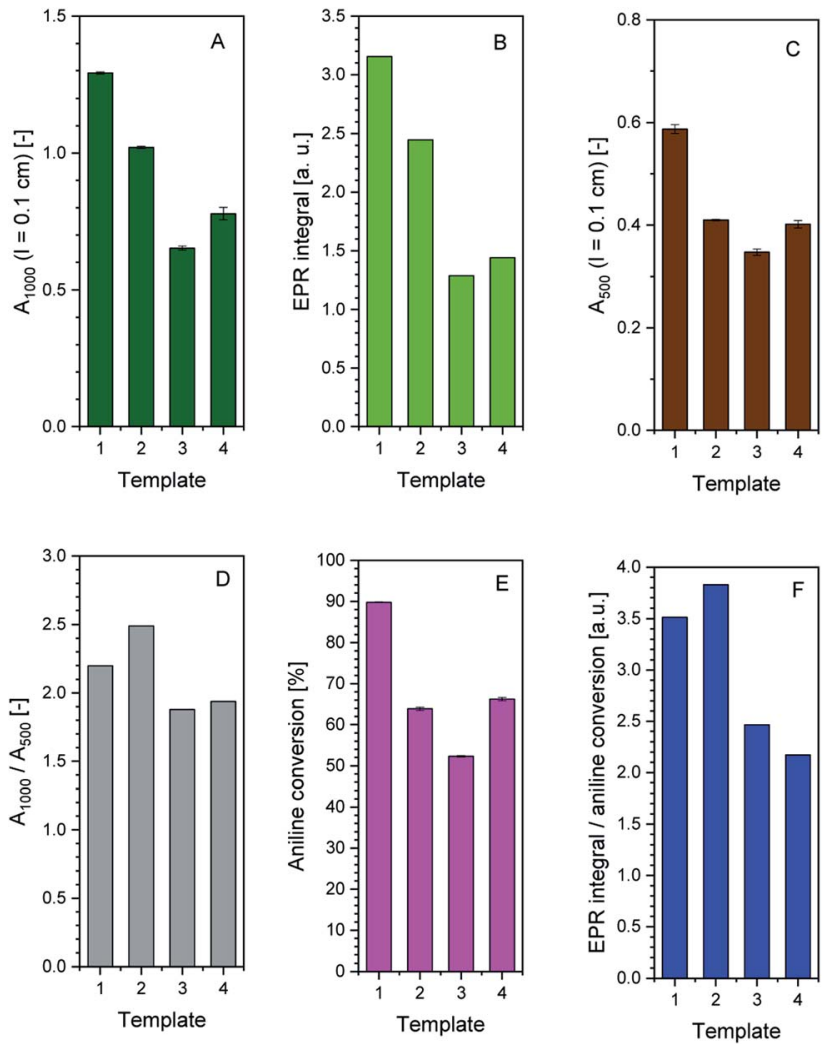

Fig. 5 Comparison of the effect the four soft templates - AOT vesicles (1), SDBS/DA (1:1) vesicles (2), SDBS micelles (3), or SPS polyelectrolyte (4) - have on the $\mathrm{HRP} / \mathrm{H}_{2} \mathrm{O}_{2}$-catalysed polymerisation of aniline in terms of UV/vis/NIR and EPR spectroscopic properties and aniline conversion. The reaction time was $24 \mathrm{~h}$, at $T \approx 25^{\circ} \mathrm{C}$, for a summary of the experimental details, see Table 1. Comparison is made on the basis of $A_{1000}(\mathrm{~A})$, EPR signal integral (B), $A_{500}$ (C), $A_{1000} /$ $A_{500}(D)$, aniline conversion (E) and ratio of EPR signal integral/aniline conversion (F).

Besides the bands characteristic for PANI-ES, the systems for all templates also show Raman bands related to structural units atypical for PANI-ES, such as phenazine (Phz)-like, $N$-phenylphenazine (safranine, Saf)-like or phenoxazine (Pho)-like units (formed by the oxidative intramolecular cyclisation of branched structures), or branched structures. These bands are observed at $\approx 1637 \mathrm{~cm}^{-1}$ (ring $\nu(\mathrm{C}-\mathrm{C})$ vibrations in $\mathrm{Phz}$, Saf or Pho-type units, mixed with $\nu(\mathrm{C}-\mathrm{C})_{\mathrm{B}}$ vibration in ordinary PANI units), 1579-1569 $\mathrm{cm}^{-1}$ (attributable to Phz-type units), $\approx 1454 \mathrm{~cm}^{-1}$ (attributable to ring $\mathrm{C}=\mathrm{C}$ stretching vibrations, possibly in short branches/chains and in substituted Phz- and $N$ phenylphenazine-type structures), and 1419-1401 $\mathrm{cm}^{-1}$ (attributed to Phz-type units). ${ }^{51}$

Based on the Raman spectroscopy measurements alone, we are unable to make any convincing conclusion on which of the chosen templates is most suited in terms of the desired products obtained. In all cases bands which are characteristic for PANI-ES are observed as dominant bands, accompanied by bands which are atypical for PANI-ES.

3.2.4. Test of inkjet-printability of the as-obtained PANI-ES suspensions and solutions. All four reaction mixtures containing soft templates were tested for their inkjetprintability on ordinary white paper by applying a previously developed protocol. ${ }^{41}$ As a result, all mixtures could be used as ink without any further pretreatment (Fig. 7). For all four mixtures, no printer nozzle clogging and only insignificant inkbleeding was observed. Therefore, they appear equally useful for possible applications.

\subsection{Possible use of cellulose nanocrystals (CNCs) as rigid templates}

3.3.1. CNC characterization. The crystalline structure of the cellulose nanocrystals (CNCs) prepared was investigated by $\mathrm{X}$-ray powder diffraction (XRD). As depicted in Fig. 8A, the CNCs had the characteristic X-ray diffraction peaks of cellulose I, with three well-defined peaks centered at $2 \theta=14.7^{\circ}, 16.4^{\circ}$ and $22.7^{\circ}$ arising from the reflections of the $(1-10),(110)$ and $(200)$ planes, respectively, and a weaker reflection at $2 \theta=34.4^{\circ}$ corresponding to the (004) plane. ${ }^{58,59}$ The presence of functional groups in the CNCs was investigated by ATR-FTIR measurements as shown in Fig. 8B. The characteristic absorption peaks of cellulose, with a broad band corresponding to -OH stretching vibrations at $3600-3200 \mathrm{~cm}^{-1}$, a less intense band located at $2902 \mathrm{~cm}^{-1}$ as a result of the $\mathrm{C}-\mathrm{H}$ groups, and narrower welldefined bands at 1337,1160 and $897 \mathrm{~cm}^{-1}$ due to $\mathrm{C}-\mathrm{O}-\mathrm{H}$ bending, C-O-C bending and $\mathrm{C}-\mathrm{O}-\mathrm{C}$ asymmetric stretching modes were observed. ${ }^{60}$ The presence of sulfate groups in CNC is supported by the strong bands at around $1033 \mathrm{~cm}^{-1},{ }^{40}$ see also Fig. S-9A, ESI. $\dagger$ According to the elemental analysis carried out (elements $\mathrm{C}, \mathrm{H}$, and $\mathrm{S}$ ), the prepared CNCs were composed of $42.2 \pm 0.11 \% \mathrm{C}, 6.1 \pm 0.05 \% \mathrm{H}$ and $0.82 \pm 0.15 \% \mathrm{~S}$, supporting the covalent coupling of sulfate groups to the surface of the CNCs, as a result of the hydrolysis of cellulose with $\mathrm{H}_{2} \mathrm{SO}_{4}$. These sulfate groups, besides providing the CNC with a negative surface charge (zeta-potential of $-37.2 \mathrm{mV}$ at $\mathrm{pH}$ of 4.3 , Fig. S9B, ESI $\dagger$ ), decreased the thermal stability of the CNCs, where the onset of thermal degradation ( $T_{\text {onset }}$, as determined by the first $10 \%$ weight loss) was found at $165.7^{\circ} \mathrm{C}$ (Fig. 8C). ${ }^{40}$ Finally, the morphology of the synthesized CNCs was characterised by transmission electron microscopy (TEM). Fig. 8D shows rodshaped particles with $135 \pm 21 \mathrm{~nm}$ in length and $7 \pm 1 \mathrm{~nm}$ in width (statistics based on counts of 40 particles).

3.3.2. Optimal reaction conditions and product characterisation. In a large number of trials defined amounts of CNC, aniline, HRPC and $\mathrm{H}_{2} \mathrm{O}_{2}$ were mixed in aqueous $\mathrm{pH}=4.3$ solution at RT to explore whether conditions exist which lead to a stable green suspension, characteristic for the formation of PANI-ES. Typical sample volumes were $400 \mu \mathrm{L}$, and the mixtures were prepared in $1.5 \mathrm{~mL}$ Eppendorf tubes with final addition of $\mathrm{H}_{2} \mathrm{O}_{2}$ to initiate the reaction (see Section 2.5.1). This screening was carried out under simple inspection by the naked eye. Although we initially prepared reaction mixtures containing CNCs under exactly the same conditions as used for the soft template experiments, i.e., $4.0 \mathrm{mM}$ aniline, $0.92 \mu \mathrm{M}$ HRPC, $4.5 \mathrm{mM} \mathrm{H}_{2} \mathrm{O}_{2}$ (see Table 1), for none of the CNC concentrations tested satisfactory products were obtained. They were both reddish and showed a lot of precipitation. This was probably 
(A)

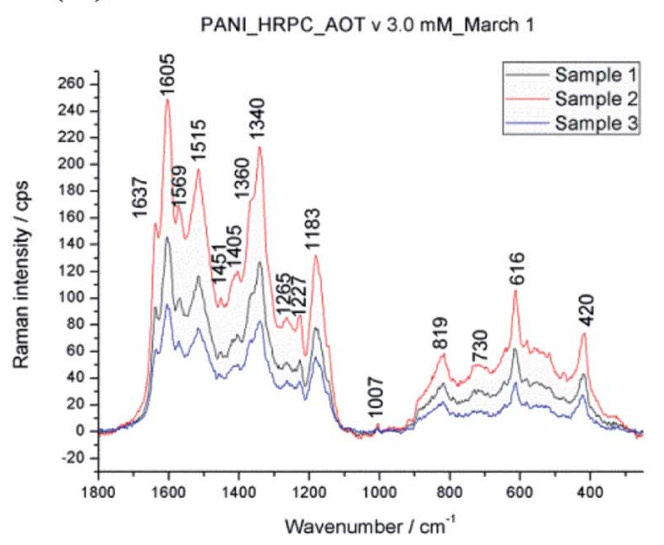

(C)

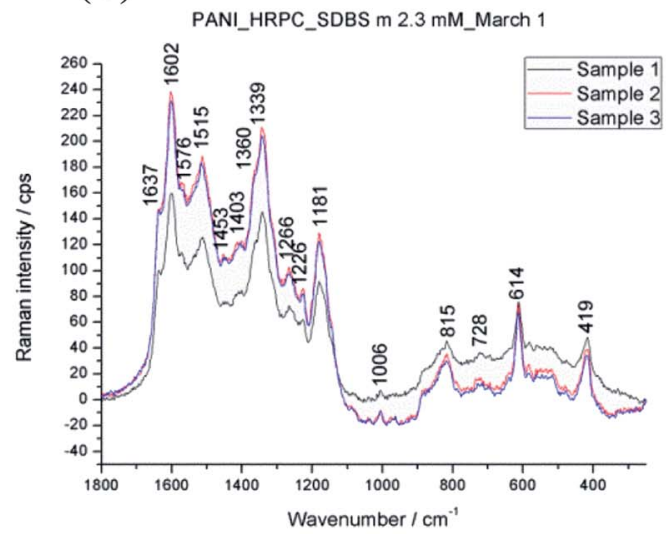

(B)

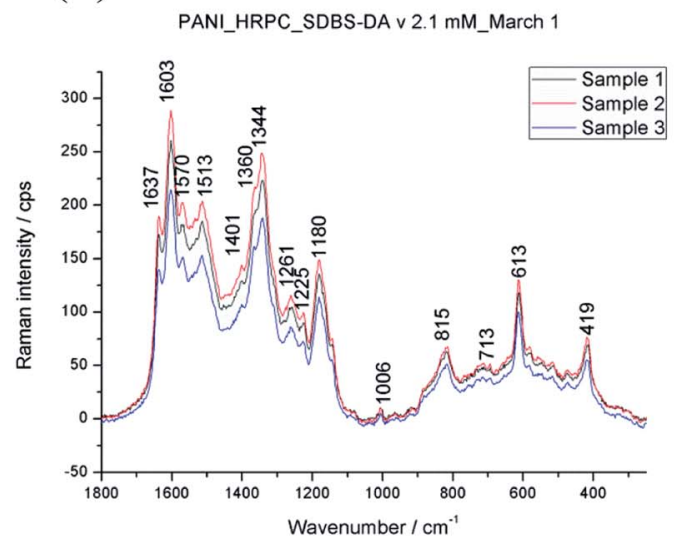

(D)

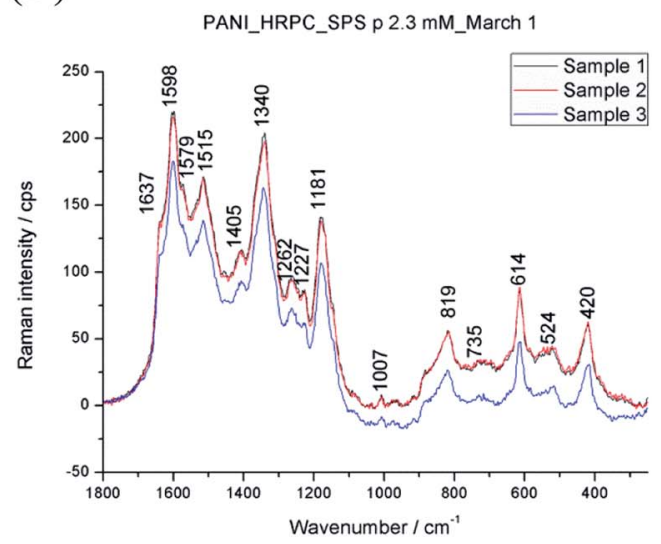

Fig. 6 Raman spectra of the different reaction mixtures run for $t=4 \mathrm{~d}$ at $T \approx 25^{\circ} \mathrm{C}$, either in the presence of AOT vesicles (A), SDBS/DA (1: 1 ) vesicles (B), SDBS micelles (C), or SPS polyelectrolyte (D) and aniline, $\mathrm{HRPC}$ and $\mathrm{H}_{2} \mathrm{O}_{2}$ at $\mathrm{pH}=4.3$. For a summary of the experimental details, see Table 1. Three spectra are shown as obtained from three separate reactions to illustrate the reproducibility.

due to the low sulfate content of the CNCs, as compared to the amount of sulfonate groups present in the soft templates. ${ }^{61}$ Therefore, other compositions were tested. A general observation was that the final addition of $\mathrm{H}_{2} \mathrm{O}_{2}$ always resulted in the formation of coloured products if aniline and HRPC were present. Depending on the experimental conditions, the initially turbid (milky) CNC suspension first turned violet and then reddish or dark-green, depending on the composition. Without CNCs, most reaction mixtures tested resulted in reddish precipitates. These observations indicate that rigid CNCs can act as templates for PANI-ES formation from aniline with HRP and $\mathrm{H}_{2} \mathrm{O}_{2}$, in a similar but apparently less efficient
(A) AOT vesicles

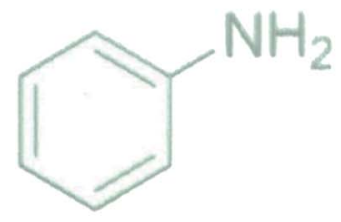

(B) SDBS/DA vesicles

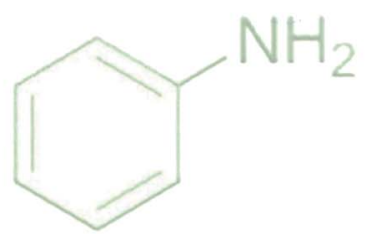

(C) SDBS micelles

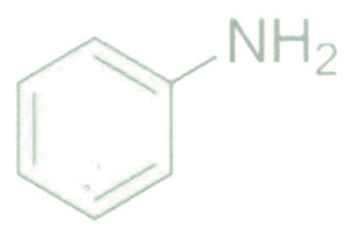

\section{(D) SPS polyelectrolyte}

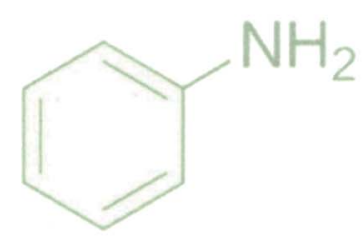

Fig. 7 Photographs of inkjet-printed patterns of aniline on white paper using the different reaction mixtures obtained from the $\mathrm{HRPC} / \mathrm{H}_{2} \mathrm{O}_{2}-$ catalysed polymerisation of aniline at $\mathrm{pH}=4.3$ and $T=25^{\circ} \mathrm{C}$ in the presence of either AOT vesicles (A), SDBS/DA (1: 1) vesicles (B), SDBS micelles (C), or SPS polyelectrolyte (D). The different reaction mixtures were used as ink after a reaction time of $44 \mathrm{~h}$. For a summary of the experimental details, see Table 1. To improve the visibility of the printed structure, the contrast of all images was modified ( $-50 \%)$ by using the standard tool of MS PowerPoint. The length of the carbon-carbon bonds in the benzene ring of the printed chemical structures of aniline was in all cases 11.5 $\mathrm{mm}$. 

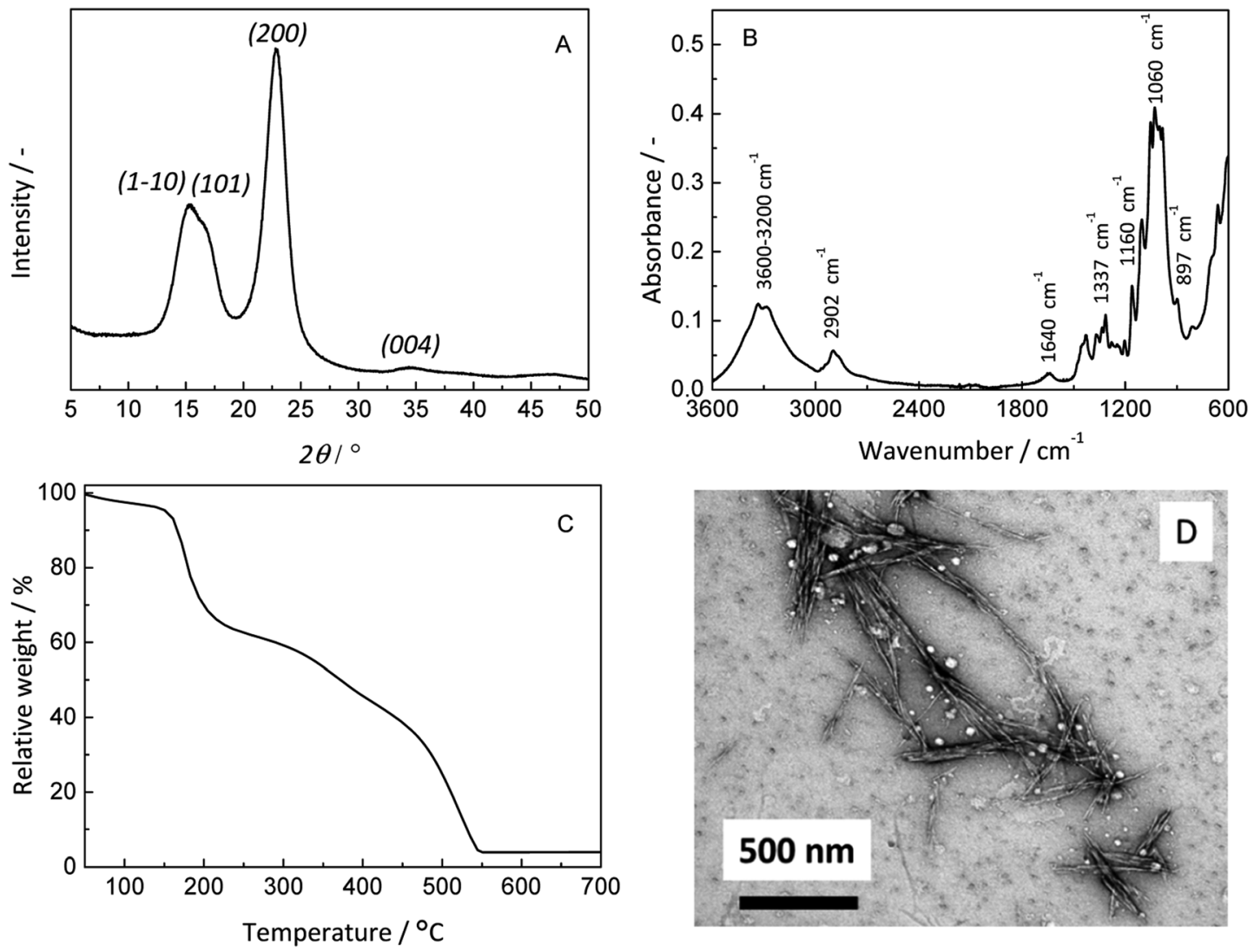

Fig. 8 Characterisation of the synthesised cellulose nanocrystals (CNCS). (A) XRD pattern; (B) ATR-FTIR spectrum; (C) trace from thermogravimetric analysis; and (D) representative TEM micrograph.

way as the soft templates investigated. As a general trend, keeping the amount of CNC, HRPC and $\mathrm{H}_{2} \mathrm{O}_{2}$ the same, the intensity of the green colour increased with increasing initial aniline concentration, see Fig. 9. Similarly, increasing the amount of CNCs or HRPC and $\mathrm{H}_{2} \mathrm{O}_{2}$ resulted in products which had a more intense green colour. For the series of experiments in which aniline or HRPC and $\mathrm{H}_{2} \mathrm{O}_{2}$ were increased, the highest concentrations tested resulted in green hydrogels (Fig. 9). We had never found such gelation in the case of soft templates. Therefore, it must be due to the type of template used or the actual amounts applied.

In order to provide insights into the spectroscopic properties of the products obtained from aniline with HRPC and $\mathrm{H}_{2} \mathrm{O}_{2}$ in the presence of $\mathrm{CNC}, \mathrm{UV} / \mathrm{vis} / \mathrm{NIR}$ absorption spectra of the reaction mixtures shown in Fig. 9 were recorded. They are shown in Fig. 10, together with spectra of several control mixtures. Notable differences are observed depending on the concentrations of CNCs, aniline, HRPC and $\mathrm{H}_{2} \mathrm{O}_{2}$. Spectra with absorption bands in the NIR region and at about $420 \mathrm{~nm}-$ characteristic for the formation of PANI-ES ${ }^{19,47}$ - were only observed for reaction mixtures containing CNCs. The best ("optimal") conditions for CNC in terms of PANI-ES formation we found with our preliminary screening were those of reaction mixture $3(\operatorname{rxn} \# 3)$. The spectrum has a clear absorption maximum at $\approx 1100 \mathrm{~nm}$ and at $\approx 420 \mathrm{~nm}$, but also a small peak at $\approx 550 \mathrm{~nm}$ (most likely originating from undesired phenazine formation).$^{48}$ The reaction is highly reproducible, as shown with three samples of the same composition, see Fig. S-10, ESI. $\dagger$ The kinetics of the reaction under optimal CNC conditions was monitored by recording the UV/vis/NIR spectrum as a function of reaction time, see Fig. 11A. The changes are qualitatively the same as observed with AOT vesicles as soft templates ${ }^{34,35}$ with the initial fast formation of a peak at $\approx 750 \mathrm{~nm}$, followed by a decrease in $A_{750}$ and an increase in absorption in the NIR region, at $\approx 1000 \mathrm{~nm}$ and at higher wavelength. In the absence of CNC, the changes in the absorption spectrum are very different, although at the beginning a peak at $\approx 750 \mathrm{~nm}$ occurred as well (rxn \# $3^{\prime}$; Fig. 11B).

The products in rxn \# 3 after $t=24 \mathrm{~h}$ have an EPR spectrum (3 in Fig. 12), as expected for the unpaired electrons present in the polaron forms of PANI-ES. For the reference reaction run without $\mathrm{CNC}\left(\mathrm{rxn} \# 3^{\prime}\right)$, an EPR spectrum could also be measured $\left(3^{\prime}\right.$ in Fig. 12). The integral, i.e., the amount of radicals, was, however, only about one third of the one for the reaction mixture with CNCs (Fig. S-11, ESI $\dagger$ ). In the case of the soft templates, the difference in EPR signal intensity between the PANI-ES products obtained under optimal conditions in the presence of template and the PANI products obtained without template is much larger. ${ }^{33}$

Determination of the amount of unreacted aniline after $24 \mathrm{~h}$ showed that the aniline conversion was only about $28 \%$, see 


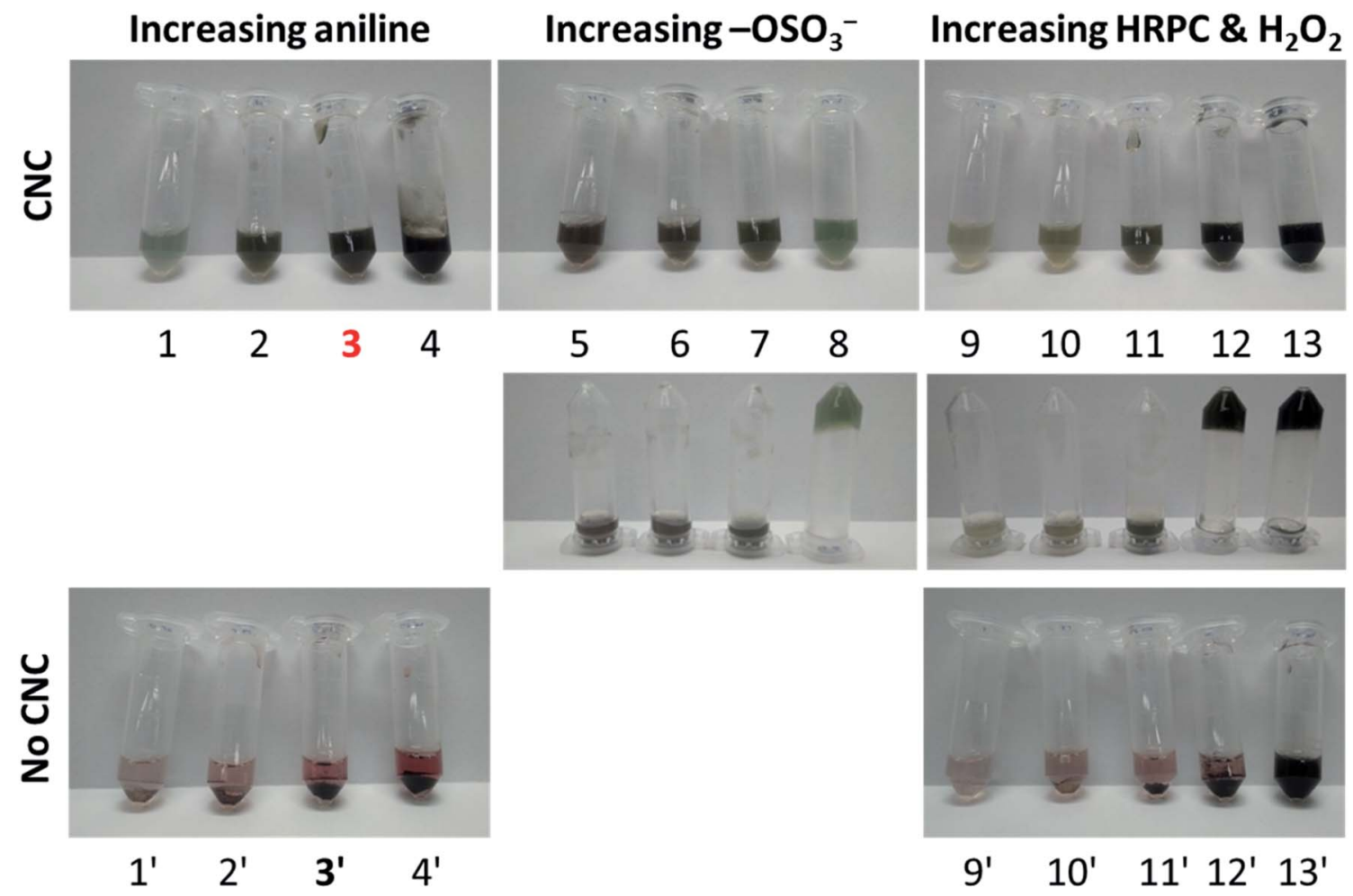

Fig. 9 Digital photographs showing the colour and appearance of some of the reaction mixtures tested $\left(r \times n\right.$ \# 1-13, $1^{\prime}-4^{\prime}$, and $\left.9^{\prime}-13^{\prime}\right)$ after a reaction time of $24 \mathrm{~h}$ for different experimental conditions at $T \approx 25^{\circ} \mathrm{C}$, see Table S-1, ESI. $\dagger$ In Table 2, the preparation and initial composition for the reaction mixture, which we considered optimal ( $r x n \# 3)$ are listed: $8.0 \mathrm{mM}$ aniline, $0.36 \mu \mathrm{M} \mathrm{HRPC}, 1.8 \mathrm{mM} \mathrm{H}{ }_{2} \mathrm{O}_{2}, 0.46 \mathrm{wt} \% \mathrm{CNC}(\mathrm{pH}=$ 4.3). Reaction mixture $3^{\prime}\left(r \times n \# 3^{\prime}\right.$ ) had the same composition as rxn \# 3, but without CNCs. The two photographs in the second row show reaction mixtures 5-13 ( $r \times n$ \# 5-13) after turning them upside down.

Fig. S-12, ESI. $\dagger$ The reason for this low yield currently is not clear. It may, however, be related to the inactivation of HRPC by the formed products. ${ }^{35}$
The synthesised CNCs consisting of surface adsorbed PANIES (abbreviated as CNC/PANI-ES) (products of rxn \# 3, see Table 2 and Fig. 9) were washed with deionised water - to get rid of the
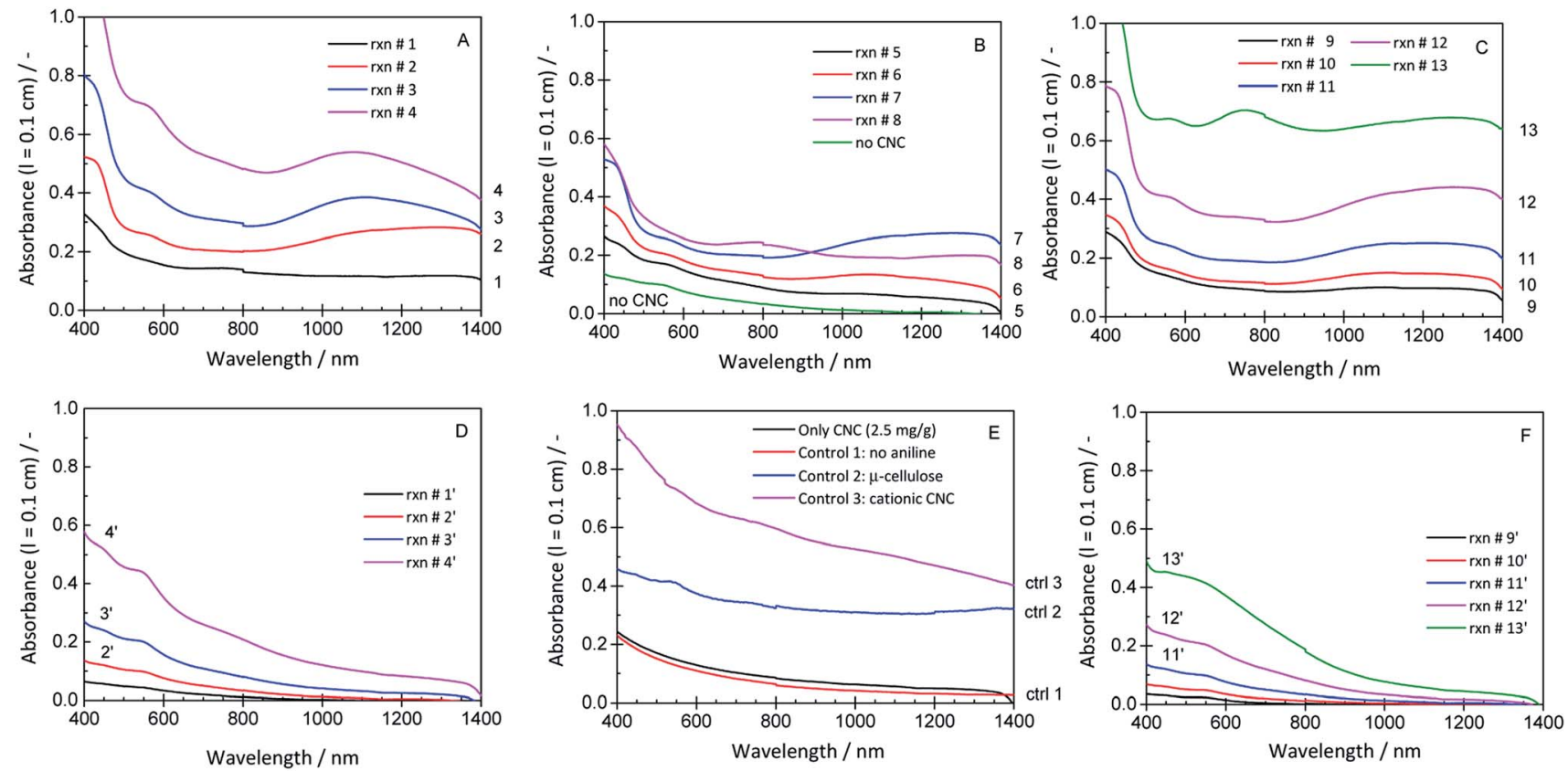

Fig. $10 \mathrm{UV} / \mathrm{vis} / \mathrm{NIR}$ absorption spectra of the same reaction mixtures shown in Fig. 9 , recorded after a reaction time of $24 \mathrm{~h}$ at $T \approx 25{ }^{\circ} \mathrm{C}$. 

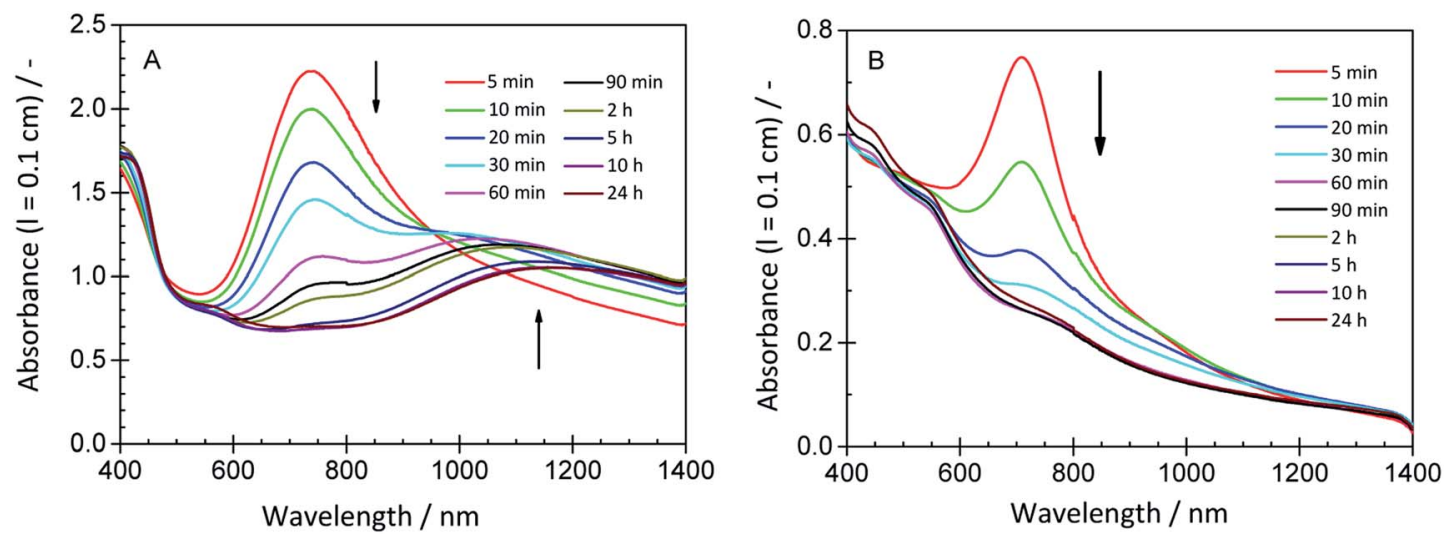

Fig. 11 Changes of the UV/vis/NIR spectrum of (A) reaction mixture 3 (rxn \# 3 of Fig. 9, "optimal" conditions for CNCs as templates) and (B) reaction mixture $3^{\prime}$ ( $r \times n \# 3^{\prime}$ of Fig. 9, absence of $\mathrm{CNC}$ ) during the course of the reaction run at $T \approx 25^{\circ} \mathrm{C}$.

buffer salt - and then analysed by HR-SEM. For this, a drop of rxn \# 3 was casted onto a silicon wafer (Fig. 13). The washed CNC/PANI-ES particles were also characterised by FTIR spectroscopy after drying (Fig. S-13, ESI $\dagger$ ). Compared to untreated CNCs (Fig. 13A), the morphology of the CNC/PANI-ES product is very similar. Higher magnification images reveal the formation of a core-sheath structure with diameters of about $20 \mathrm{~nm}$, where the PANI molecules remain wrapped around individual CNC particles, similarly to what has been observed previously for a CNC/polypyrrole system, ${ }^{44}$ whereby in that case polypyrrole was synthesised through non-enzymatic, chemical oxidation. The morphology of the CNC/PANI-ES particles is in clear contrast to the morphologies determined for PANI polymerised under the same experimental conditions in a CNC-free solution (see Fig. S-14A, ESI $\dagger$ ) or for a mixture of CNCs with aniline before addition of HRP and $\mathrm{H}_{2} \mathrm{O}_{2}$ (Fig. S-14B, ESI $\dagger$ ).

Concerning the FTIR spectrum of CNC/PANI-ES product (Fig. $\mathrm{S}$ $14, \mathrm{ESI}_{\dagger}^{\dagger}$ ), there is no notable difference to CNC. The spectrum is dominated by vibrational bonds originating from CNC.

\subsection{Concluding remarks}

From our previous comparative investigations of the Trametes versicolor laccase $/ \mathrm{O}_{2}$-catalysed, template-assisted oxidation of PADPA to PANI-ES-like oligo(PADPA) products at $\mathrm{pH}=3.5$, we concluded that AOT vesicles are somewhat superior soft templates if compared to SDBS/DA (1:1) vesicles, and more so if compared to SPS polyelectrolyte, or SDBS micelles. The use of SDBS micelles appeared particularly disadvantageous because considerably higher amounts of laccase were required as compared to the other templates used. ${ }^{41}$ This earlier finding agrees to some extent with what we found in the present work for the $\mathrm{HRPC} / \mathrm{H}_{2} \mathrm{O}_{2}$-catalysed polymerisation of aniline to PANI-ES products. The two types of vesicles were again superior if compared to SDBS micelles; the presence of the micelles resulted in a lower extent of aniline conversion (Fig. 5E). The reason for this is probably the lower operational stability of HRPC (and laccase) in the presence of SDBS micelles as compared to AOT or SDBS/DA $(1: 1)$ vesicles. In the presence of one of the two types of vesicles, HRPC is indeed very stable if stored without aniline and
$\mathrm{H}_{2} \mathrm{O}_{2},{ }^{33,35}$ while the enzyme is considerably less stable in the presence of SDBS micelles. ${ }^{33}$ The same order of stability was also found for HRPC in the reaction mixture during the reaction (Fig. S-15†). In terms of EPR signal intensity, indicative for the formation of the polaron form of PANI-ES, the measurements indicate that the two vesicle systems are again good choices (Fig. 5B and F). Neglecting the issue of enzyme inactivation, the differences between the two vesicle systems and the SPS polyelectrolyte or SDBS micelles are, however, not as significant to show clear and convincing differences in the Raman spectra of the final reaction products (Fig. 6). Moreover, for all four soft templates, inkjet printability of the as-obtained solutions or suspensions was demonstrated (Fig. 7), confirming their suitability for processes in which finely dispersed PANI-ES particles are required. In terms of possible applications, it is the final performance of the applied products which counts at the end. In this respect, in one application - the coating of glassy carbon electrodes with electroactive PANI-ES synthesised with HRPC/ $\mathrm{H}_{2} \mathrm{O}_{2}$ from aniline in the presence of AOT vesicles - it was shown that AOT vesicles may indeed be a good choice. ${ }^{37}$

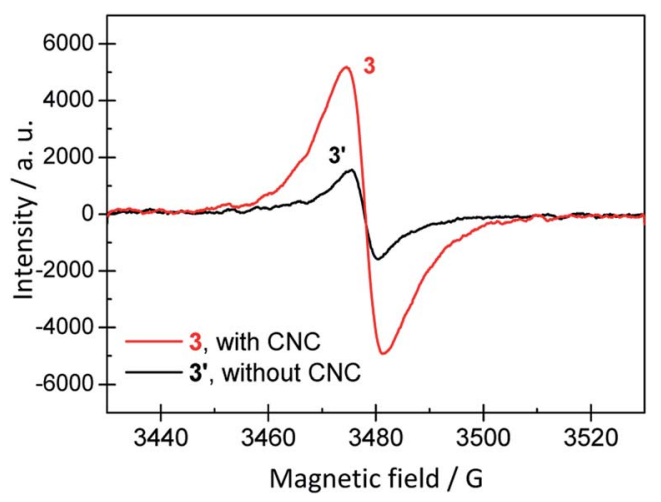

Fig. 12 EPR spectrum of the reaction mixture 3 (rxn \# 3 of Fig. 9, "optimal" conditions for CNCs as templates), recorded after a reaction time of $24 \mathrm{~h}$ at $T \approx 25^{\circ} \mathrm{C}$. For comparison, a reaction mixture of identical initial composition, but without CNC ( $\left.3^{\prime}\right)$ was also analysed after $24 \mathrm{~h}$ at $T \approx 25^{\circ} \mathrm{C}$. 

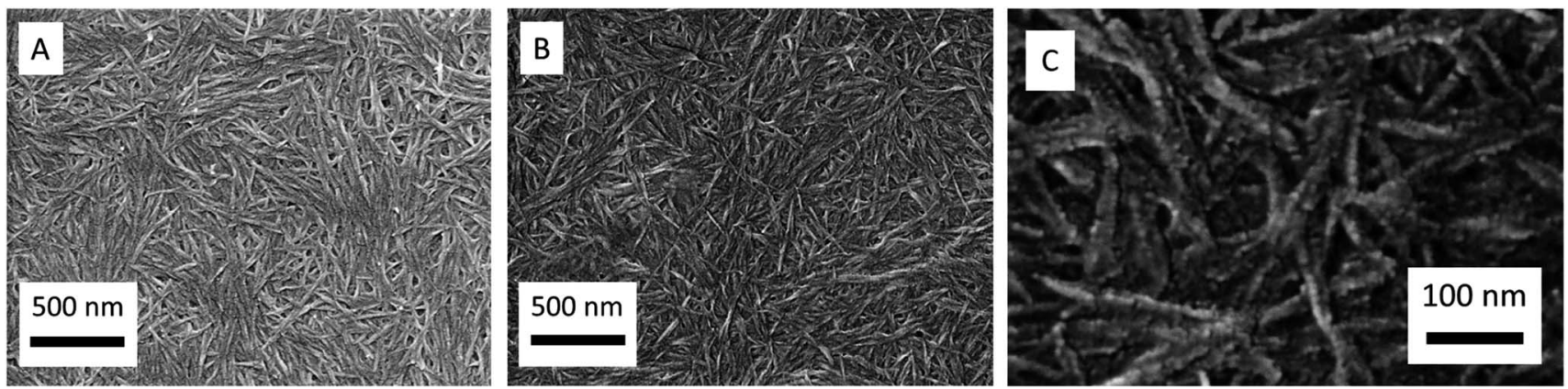

Fig. 13 Representative HR-SEM images of (A) the prepared CNCs and (B) CNCs containing surface adsorbed PANI-ES products, as obtained after a reaction time of $24 \mathrm{~h}$ at $T \approx 25^{\circ} \mathrm{C}$ from reaction mixture 3 (rxn \# 3 of Fig. 9, "optimal" conditions for CNCs as templates). (C) is a magnification of a part of image $(B)$

Moving from vesicles, micelles and polyelectrolyte to the more rigid template CNCs showed that replacement of one of the soft template molecule types by $\mathrm{CNC}$ is not as simple as one may think at first. Although CNCs have a negatively charged surface originating from sulfate groups, it was not clear whether the charge density would be appropriate for acting as useful template, and whether the rigidity of the CNCs would favour PANI-ES formation. The preliminary results obtained indicate that the $\mathrm{HRPC} / \mathrm{H}_{2} \mathrm{O}_{2}$-catalysed formation of PANI-ES products from aniline on CNCs is possible. Although there is still room for improvement, the method can be considered as alternative, enzymatic approach to the conventional methods in which PANI is synthesized chemically on cellulose nanocrystals for the development of conductive textile surfaces, ${ }^{62}$ flexible papers ${ }^{63}$ or more sophisticated conductive materials. ${ }^{64}$

\section{Conflicts of interest}

There are no conflicts to declare.

\section{Acknowledgements}

Financial support for this work was provided by the Swiss National Science Foundation projects 200020_150254 and IZ73Z0_152457 (P. W., S. S.-L., G. Ć.-M., D. B.-B., and M. M.-R.), the Ministry of Education, Science and Technological Development of Serbia project OI172043 (G. Ć.-M., D. B.-B. and M. M.R.) and through the generous fellowships given to K. K (National Institute of Technology, Faculty Research Abroad Program, Japan) and T. F. (TOBITATE! Young ambassador program from The Japan Public-Private Partnership Student Study Abroad Program) for their stay at ETH. E. L. thanks The Spanish Ministry of Education, Culture and Sport for the "José Castillejo" mobility grant and Dr Elena Tervoort-Gorokhovat for the assistance provided during the SEM analyses.

\section{Notes and references}

1 J. Stejskal, M. Trchová, P. Bober, P. Humpolíček, V. Kašpárková, I. Sapurina, M. A. Shishov and M. Varga, Conducting Polymers: Polyaniline, in Encyclopedia of
Polymer Science and Technology, John Wiley \& Sons, 4th edn, 2015.

2 G. G. Wallace, G. M. Spinks, L. A. P. Kane-Maguire and P. R. Teasdale, Conductive Electroactive Polymers: Intelligent Polymer Systems, CRC Press, 3rd edn, 2009.

3 G. Ćirić-Marjanović, Recent advances in polyaniline research: Polymerization mechanisms, structural aspects, properties and applications, Synth. Met., 2013, 177, 1-47.

4 E. M. Geniès, M. Lapowski and J. F. Penneau, Cyclic Voltammetry of Polyaniline: Interpretation of the Middle Peak, J. Electroanal. Chem., 1988, 249, 97-107.

5 F. Lux, Properties of electronically conductive polyaniline: a comparison between well-known literature data and some recent experimental findings, Polymer, 1994, 35, 2915-2936.

6 J. P. Sadighi, R. A. Smith and S. L. Buchwald, PalladiumCatalyzed Synthesis of Monodisperse, Controlled-Length, and Functionalized Oligoanilines, J. Am. Chem. Soc., 1998, 120, 4960-4976.

7 J. Stejskal, A. Riede, D. Hlavatá, J. Prokeš, M. Helmstedt and P. Holler, The effect of polymerization temperature on molecular weight, crystallinity, and electrical conductivity of polyaniline, Synth. Met., 1998, 96, 55-61.

8 Z. D. Zujovic, L. Zhang, G. A. Bowmaker, P. A. Kilmartin and J. Travas-Sjedic, Self-Assembled, Nanostructured Aniline Oxidation Products: A Structural Investigation, Macromolecules, 2008, 41, 3125-3135.

9 S. P. Surwade, V. Dua, N. Manohar, S. K. Manohar, E. Beck and J. P. Ferraris, Oligoaniline intermediates in the anilineperoxydisulfate system, Synth. Met., 2009, 159, 445-455.

10 I. Y. Sapurina and J. Stejskal, The effect of $\mathrm{pH}$ on the oxidative polymerization of aniline and the morphology and properties of products, Russ. Chem. Rev., 2010, 79, 1123-1143.

11 H. D. Tran, J. M. D'Arcy, P. J. Beltramo, V. A. Strong and R. B. Kaner, The oxidation of aniline to produce "polyaniline": a process yielding many different nanoscale structures, J. Mater. Chem., 2011, 21, 3534-3550.

12 A. G. MacDiarmid and A. J. Epstein, Polyanilines: A Novel Class of Conducting Polymers, Faraday Discuss. Chem. Soc., 1989, 88, 317-332. 
13 N. Gospodinova and L. Terlemezyan, Conducting Polymers Prepared by Oxidative Polymerization: Polyaniline, Prog. Polym. Sci., 1998, 23, 1443-1484.

14 A. G. MacDiarmid, J.-C. Chiang, M. Halpern, W.-S. Huang, S.-L. Mu, N. L. D. Somasiri, W. Wu and S. I. Yaniger, Polyaniline: Interconversion of Metallic and Insulating Forms, Mol. Cryst. Liq. Cryst., 1985, 121, 173-180.

15 A. G. MacDiarmid, J.-C. Chiang, W. Huang, B. D. Humphrey and N. L. D. Somasiri, Polyaniline: Protonic Acid Doping to the Metallic Regime, Mol. Cryst. Liq. Cryst., 1985, 125, 309318.

16 W. W. Focke, G. E. Wnek and Y. Wei, Influence of Oxidation State, pH, and Counterion on the Conductivity of Polyaniline, J. Phys. Chem., 1987, 91, 5813-5818.

17 Y. Cao, P. Smith and A. J. Heeger, Counter-ion induced processibility of conducting polyaniline and of conducting polyblends of polyaniline in bulk polymers, Synth. Met., 1992, 48, 91-97.

18 Y. Xia, A. G. MacDiarmid and A. J. Epstein, Camphorsulfonic Acid Fully Doped Polyaniline Emeraldine Salt: In Situ Observation of Electronic and Conformational Changes Induced by Organic Vapors by an Ultraviolet/Visible/NearInfrared Spectroscopic Method, Macromolecules, 1994, 27, 7212-7214.

19 Y. Xia, J. M. Wiesinger, A. G. MacDiarmid and A. J. Epstein, Camphorsulfonic Acid Fully Doped Polyaniline Emeraldine Salt: Conformations in Different Solvents Studied by an Ultraviolet/Visible/Near-Infrared Spectroscopic Method, Chem. Mater., 1995, 7, 443-445.

20 M. Zagorska, I. Kulszewicz-Bajer, O. Blet, P. Zawirska, B. Dufour, P. Rannou and A. Pron, Solution processible poly(aniline) via doping with diesters of sulfosuccinic acid, Synth. Met., 2003, 138, 543-548.

21 K.-S. Lee, T. Hino and N. Kuramoto, Highly Conductive Polyaniline Doped with DEHSSA Synthesized in Different Protonic Acids, Chem. Lett., 2007, 36, 340-341.

22 J. Stejskal and R. G. Gilbert, Polyaniline. Preparation of a Conducting Polymer (IUPAC Technical Report), Pure Appl. Chem., 2002, 74, 857-867.

23 Already in 1935 it was shown that aniline oxidation not only is possible with a strong chemical oxidant in very acidic solutions, but also by using horseradish peroxidase (HRP) and hydrogen peroxide $\left(\mathrm{H}_{2} \mathrm{O}_{2}\right)$ at much milder $\mathrm{pH}$ values $(\mathrm{pH}=4.5)$. However, the products obtained at the end of the reaction in the experiments carried out at that time with $\mathrm{HRP} / \mathrm{H}_{2} \mathrm{O}_{2}$ were a brown solid which gradually separated and then was filtered off. The product proved to be a complex mixture of related substances...: P. J. G. Mann and B. C. Saunders, Studies in Peroxidase Action I. - The Oxidation of Aniline, Proc. R. Soc. London, Ser. B, 1935, 119, 47-60.

24 L. A. Samuelson, A. Anagnostopoulos, K. S. Alva, J. Kumar and S. K. Tripathy, Biologically Derived Conducting and Water Soluble Polyaniline, Macromolecules, 1998, 31, 4376-4378.

25 W. Liu, J. Kumar, S. Tripathy, K. J. Senecal and L. Samuelson, Enzymatically Synthesized Conducting Polyaniline, J. Am. Chem. Soc., 1999, 121, 71-78.
26 W. Liu, A. L. Cholli, R. Nagarajan, J. Kumar, S. Tripathy, F. F. Bruno and L. Samuelson, The Role of Template in the Enzymatic Synthesis of Conducting Polyaniline, J. Am. Chem. Soc., 1999, 121, 11345-11355.

27 I. Y. Sakharov, A. C. Vorobiev and J. J. Castillo Leon, Synthesis of polyelectrolyte complexes of polyaniline and sulfonated polystyrene by palm tree peroxidase, Enzyme Microb. Technol., 2003, 33, 661-667.

28 P. Nickels, W. U. Dittmer, S. Beyer, J. P. Kotthaus and F. C. Simmel, Polyaniline nanowire synthesis templated by DNA, Nanotechnology, 2004, 15, 1524-1529.

29 Y. Shen, J. Sun, J. Wu and Q. Zhou, Synthesis and Characterization of Water-Soluble Conducting Polyaniline by Enzyme Catalysis, J. Appl. Polym. Sci., 2005, 96, 814-817.

30 A. V. Caramyshev, E. G. Evtushenko, V. F. Ivanov, A. R. Barceló, M. G. Roig, V. L. Shnyrov, R. B. van Huystee, I. N. Kurochkin, A. K. Vorobiev and I. Y. Sakharov, Synthesis of Conducting Polyelectrolyte Complexes of Polyaniline and Poly(2-acrylamido-3-methyl-1propanesulfonic acid) Catalyzed by $\mathrm{pH}$-Stable Palm Tree Peroxidase, Biomacromolecules, 2005, 6, 1360-1366.

31 W. Liu, J. Kumar, S. Tripathy and L. A. Samuelson, Enzymatic Synthesis of Conducting Polyaniline in Micelle Solutions, Langmuir, 2002, 18, 9696-9704.

32 V. Rumbau, J. A. Pomposo, J. A. Alduncin, H. Grande, D. Mecerreyes and E. Ochoteco, A new bifunctional template for the enzymatic synthesis of conducting polyaniline, Enzyme Microb. Technol., 2007, 40, 1412-1421.

33 Z. Guo, H. Rüegger, R. Kissner, T. Ishikawa, M. Willeke and P. Walde, Vesicles as Soft Templates for the Enzymatic Polymerization of Aniline, Langmuir, 2009, 25, 11390-11405.

34 Z. Guo, N. Hauser, A. Moreno, T. Ishikawa and P. Walde, AOT vesicles as templates for the horseradish peroxidase-triggered polymerization of aniline, Soft Matter, 2011, 7, 180-193.

35 K. Junker, G. Zandomeneghi, Z. Guo, R. Kissner, T. Ishikawa, J. Kohlbrecher and P. Walde, Mechanistic aspects of the horseradish peroxidase-catalysed polymerisation of aniline in the presence of AOT vesicles as templates, RSC Adv., 2012, 2, 6478-6495.

36 K. Junker, I. Gitsov, N. Quade and P. Walde, Preparation of aqueous polyaniline-vesicle suspensions with class III peroxidases. Comparison between horseradish peroxidase isoenzyme C and soybean peroxidase, Chem. Pap., 2013, 67, 1028-1047.

37 I. Pašti, M. Milojević-Rakić, K. Junker, D. Bajuk-Bogdanović, P. Walde and G. Ćirić-Marjanović, Superior capacitive properties of polyaniline produced by a one-pot peroxidase/ $\mathrm{H}_{2} \mathrm{O}_{2}$-triggered polymerization of aniline in the presence of AOT vesicles, Electrochim. Acta, 2017, 258, 834-841.

38 J. F. Revol, H. Bradford, J. Giasson, R. H. Marchessault and D. G. Gray, Helicoidal self-ordering of cellulose microfibrils in aqueous suspension, Int. J. Biol. Macromol., 1992, 14, 170-172.

39 A. Dufresne, Nanocellulose: a new ageless bionanomaterial, Mater. Today, 2013, 16, 220-227. 
40 N. Lin and A. Dufresne, Surface chemistry, morphological analysis and properties of cellulose nanocrystals with gradiented sulfation degrees, Nanoscale, 2014, 6, 5384-5393.

41 K. Kashima, T. Fujisaki, S. Serrano-Luginbühl, R. Kissner, A. Janošević Ležaić, D. Bajuk-Bogdanović, G. ĆirićMarjanović, S. Busato, T. Ishikawa and P. Walde, Effect of Template Type on the Trametes versicolor Laccase-Catalyzed Oligomerization of the Aniline Dimer $p$ Aminodiphenylamine (PADPA), ACS Omega, 2019, 4, 29312947.

42 E. Lizundia, E. Fortunati, F. Dominici, J. L. Vilas, L. M. León, I. Armentano, L. Torre and J. M. Kenny, PLLA-grafted cellulose nanocrystals: Role of the CNC content and grafting on the PLA bionanocomposite film properties, Carbohydr. Polym., 2016, 142, 105-113.

43 M. Hasani, E. D. Cranston, G. Westman and D. G. Gray, Cationic surface functionalization of cellulose nanocrystals, Soft Matter, 2008, 4, 2238-2244.

44 E. Lizundia, T.-D. Nguyen, J. L. Vilas, W. Y. Hamad and M. J. MacLachlan, Chiroptical, morphological and conducting properties of chiral nematic mesoporous cellulose/polypyrrole composite films, J. Mater. Chem. A, 2017, 5, 19184-19194.

45 N. Lin, A. Gèze, D. Wouessidjewe, J. Huang and A. Dufresne, Biocompatible Double-Membrane Hydrogels from Cationic Cellulose Nanocrystals and Anionic Alginate as Complexing Drugs Codelivery, ACS Appl. Mater. Interfaces, 2016, 8, 6880-6889.

46 H. B. Dunford and J. S. Stillman, On the Function and Mechanism of Action of Peroxidases, Coord. Chem. Rev., 1976, 19, 187-251.

47 G. M. do Nascimento and M. A. de Souza, Spectroscopy of Nanostructured Conducting Polymers, in Nanostructured Conductive Polymers, ed. A. Eftekhari, John Wiley \& Sons, Chichester, 2010, ch. 8, pp. 341-373.

48 S. Luginbühl, M. Milojević-Rakić, K. Junker, D. BajukBogdanović, I. Pašti, R. Kissner, G. Ćirić-Marjanović and P. Walde, The influence of anionic vesicles on the oligomerization of $p$-aminodiphenylamine catalyzed by horseradish peroxidase and hydrogen peroxide, Synth. Met., 2017, 226, 89-103.

49 V. I. Krinichnyi, H.-K. Roth, M. Schrödner and B. Wessling, EPR study of polyaniline highly doped by p-toluenesulfonic acid, Polymer, 2006, 47, 7460-7468.

50 B. Rakvin, D. Carić, M. Andreis, K. Junker and P. Walde, EPR Study of Polyaniline Synthesized Enzymatically in the Presence of Submicrometer-Sized AOT Vesicles, J. Phys. Chem. B, 2014, 118, 2205-2213.

51 G. Ćirić-Marjanović, M. Trchová and J. Stejskal, The chemical oxidative polymerization of aniline in water: Raman spectroscopy, J. Raman Spectrosc., 2008, 39, 13751387.
52 A. Janoševic Ležaić, S. Luginbühl, D. Bajuk-Bogdanović, I. Pašti, R. Kissner, B. Rakvin, P. Walde and G. ĆirićMarjanović, Insight into the template effect of vesicles on the laccase-catalyzed oligomerization of $N$-phenyl-1,4phenylenediamine from Raman spectroscopy and cyclic voltammetry measurements, Sci. Rep., 2016, 6, 30724.

53 M. Cochet, G. Louarn, S. Quillard, J. P. Buisson and S. Lefrant, Theoretical and experimental vibrational study of emeraldine in salt form. Part II, J. Raman Spectrosc., 2000, 31, 1041-1049.

54 G. Socrates, Infrared and Raman Characteristic Group Frequencies, John Wiley \& Sons, New York, 2001, p. 220.

55 H. G. M. Edwards, D. R. Brown, J. A. Dale and S. Plant, Raman spectroscopy of sulfonated polystyrene resins, Vib. Spectrosc., 2000, 24, 213-224.

56 M. Bláha, J. Zednik and J. Vohlídal, Self-doping of polyaniline prepared with the $\mathrm{FeCl}_{3} / \mathrm{H}_{2} \mathrm{O}_{2}$ system and the origin of the Raman band of emeraldine salt at around $1375 \mathrm{~cm}^{-1}$, Polym. Int., 2015, 64, 1801-1807.

57 M. Trchová, Z. Morávková, J. Dybal and J. Stejskal, Detection of Aniline Oligomers on Polyaniline-Gold Interface using Resonance Raman Scattering, ACS Appl. Mater. Interfaces, 2014, 6, 942-950.

58 N. Lin, C. Bruzzese and A. Dufresne, TEMPO-Oxidized Nanocellulose Participating as Crosslinking Aid for Alginate-Based Sponges, ACS Appl. Mater. Interfaces, 2012, 4, 4948-4959.

59 P. Lu and Y. Lo Hsieh, Cellulose isolation and core-shell nanostructures of cellulose nanocrystals from chardonnay grape skins, Carbohydr. Polym., 2012, 87, 2546-2553.

60 E. Lizundia, J. L. Vilas and L. M. León, Crystallization, structural relaxation and thermal degradation in Poly( $\mathrm{L}^{-}$ lactide)/cellulose nanocrystal renewable nanocomposites, Carbohydr. Polym., 2015, 123, 256-265.

61 For AOT, SDBS and SPS, the calculated mass fractions of sulfur are $7.6 \%, \approx 9 \%$, and $15 \%$, respectively. For the CNCs prepared it was $0.82 \pm 0.15 \%$.

62 Z. Stempien, T. Rybicki, M. Kozanecki and M. I. Szynkowska, In situ deposition of polyaniline and polypyrrole electroconductive layers on textile surfaces by the reactive ink-jet printing technique, Synth. Met., 2015, 202, 49-62.

63 D. A. Gopakumar, A. R. Pai, Y. B. Pottathara, D. Pasquini, L. C. de Morais, M. Luke, N. Kalarikkal, Y. Grohens and S. Thomas, Cellulose Nanofiber-Based Polyaniline Flexible Papers as Sustainable Microwave Absorbers in the X-Band, ACS Appl. Mater. Interfaces, 2018, 10, 20032-20043.

$64 \mathrm{X}$. Wu, C. Hu, H. Xu, X. Zhang and Z. Zhou, Biotemplate Synthesis of Polyaniline@Cellulose Nanowhiskers/Natural Rubber Nanocomposites with 3D Hierarchical Multiscale Structure and Improved Electrical Conductivity, ACS Appl. Mater. Interfaces, 2014, 6, 21078-21085. 